ISSN: 0213-2060

DOI: https://doi.org/10.14201/shhme201735173103

\title{
REIVINDICACIÓN DE ESTATUS Y COSTUMBRES FORÁNEAS EN EL REGISTRO FUNERARIO MEDIEVAL CASTELLANO. A PROPÓSITO DE DOS CASOS DE CANTABRIA
}

\author{
Claim of Status and Foreign Customs in the Medieval Funerary Record. \\ Apropos of Two Examples of Cantabria \\ Enrique GUTIÉRREZ CUENCA \\ Doctor en Historia. C. e.: egcuenca@gmail.com
}

Recibido: 2016-04-10

Revisado: 2017-01-04

Aceptado: 2017-05-09

RESUMEN: Descripción e interpretación de dos contextos funerarios de Cantabria de los siglos XII-XIII: las sepulturas con «espuelas doradas» de San Martín de Elines y la tumba con vasijas incensario de Santa María de la Ascensión de Castro Urdiales. El primer caso se relaciona con el desarrollo de la caballería noble en Castilla durante el siglo XIII, mientras que en el segundo caso se analizan los motivos de la presencia de una práctica funeraria ajena a la tradición local.

Palabras clave: Arqueología; Funerales; Sepultura; Caballero; Extranjero; Espuelas doradas; Vasijas incensario.

ABSTRACT: Description and interpretation of two funerary contexts from $12^{\text {th }}-13^{\text {th }}$ Centuries Cantabria: the burials with "golden spurs» in San Martín de Elines and the grave with incense pots in Santa María de la Ascensión of Castro Urdiales. The first case connects with the development of noble cavalry in Castile in $13^{\text {th }}$ Century, whereas in the second one the reasons for the presence of a funerary custom unconnected with the local tradition are analysed.

Keywords: Archaeology; Funeral; Grave; Knight; Foreign; Golden spurs; Incense pots. 
REIVINDICACIÓN DE ESTATUS Y COSTUMBRES FORÁNEAS EN EL REGISTRO FUNERARIO MEDIEVAL CASTELLANO. A PROPÓSITO DE DOS CASOS DE CANTABRIA ENRIQUE GUTIÉRREZ CUENCA

SUMARIO: 0 Introducción. 1 Las espuelas doradas de San Martín de Elines. 2 Las «espuelas doradas» como distintivo de estatus en Castilla. 3 Las vasijas incensario de Santa María de Castro Urdiales. 4 Un gesto funerario foráneo en un puerto castellano. 5 Conclusiones. 6 Referencias bibliográficas.

\section{INTRODUCCIÓN}

Si durante cerca de cuatrocientos años una de las características que definen el registro funerario en Castilla es la ausencia de objetos acompañando a los difuntos en las sepulturas, al final de la Edad Media vuelven a aparecer tumbas con ajuar. Esta práctica no llegará a alcanzar la frecuencia conocida en los tiempos altomedievales, pero algunos casos ofrecen información relevante para una mejor comprensión e interpretación de los comportamientos funerarios en claves social y cultural.

Un buen ejemplo lo constituyen dos casos documentados en Cantabria que hemos tenido oportunidad de estudiar en nuestra tesis doctoral ${ }^{1}$, aunque no con el detalle que merecen, y en cuyo análisis profundizamos en este trabajo. Nos referimos a las sepulturas con «espuelas doradas» de San Martín de Elines y a la presencia de vasijas incensario en una tumba de Santa María de la Asunción de Castro Urdiales.

Se trata de manifestaciones que se pueden fechar entre los siglos XII y XIII, ciertamente singulares, relevantes en sí mismas por su rareza en el contexto peninsular -sobre todo las vasijas de Castro-, pero también por la lectura histórica que permiten realizar. Por ello, este estudio tiene el necesario aparato descriptivo, pero interesa sobre todo la discusión de los datos. Unos datos procedentes - conviene tenerlo en cuenta- de la Arqueología de gestión, con lo que se contribuye además a la incorporación al debate académico de la documentación generada desde este ámbito.

Nos interesa, sobre todo, mostrar que no se trata de casos aislados y que precisamente en su repetición y en la presencia de pautas y regularidades encontramos parte de la información necesaria para interpretarlos de forma correcta. El apoyo de los testimonios ofrecidos por la documentación escrita y la documentación iconográfica facilita la labor, sobre todo si pensamos en las dificultades que el mismo proceso entrańa en el estudio de otras épocas donde el soporte de otras fuentes escasea, como sucede con la más Alta Edad Media. Los ejemplos seleccionados ofrecen interesantes posibilidades de interpretación con un enfoque de este tipo, pudiéndose alcanzar a vislumbrar los mensajes que se intentan transmitir a través de los funerales y de los gestos expresados en las sepulturas. $\mathrm{Al}$ mismo tiempo, su estudio nos permite reflexionar sobre el papel que desempeñan los objetos en el registro funerario a partir de un análisis contextual basado en la interdisciplinariedad como el que reclama $\mathrm{H}$. Härke². Aunque no somos demasiado partidarios de los postulados postprocesualistas, es innegable que las motivaciones para el depósito

1 Gutiérrez Cuenca, Enrique. Génesis y evolución del cementerio medieval en Cantabria. Santander: Universidad de Cantabria, 2015 [doi: hdl.handle.net/10803/311798].

2 Härke, Heinrich. «Grave goods in early medieval burials: messages and meanings». Mortality, 2014, vol. 19, n. ${ }^{\circ} 1$, pp. 41-60. 
REIVINDICACIÓN DE ESTATUS Y COSTUMBRES FORÁNEAS EN EL REGISTRO FUNERARIO MEDIEVAL CASTELLANO. A PROPÓSITO DE DOS CASOS DE CANTABRIA ENRIQUE GUTIÉRREZ CUENCA

de objetos junto a los difuntos es una cuestión compleja, vinculada a motivaciones diversas, que pueden cambiar dependiendo de muchos factores. La aparente ostentación suntuaria puede ocultar un complejo trasfondo socio-político. O lo que en un lugar determinado puede ser una demostración de la posición social, exportado a otro ámbito geográfico puede ser una reivindicación de la pertenencia a una comunidad, un indicador étnico en el sentido amplio del término.

\section{Las espuelas doradas de San Martín de Elines}

Durante las obras de restauración de la colegiata de San Martín de Elines (Valderredible, Cantabria), realizadas en 2001 bajo el patrocinio de la Fundación Santa María la Real, se llevaron a cabo excavaciones arqueológicas que permitieron documentar la planta de una iglesia prerrománica y un cementerio medieval de prolongado uso ${ }^{3}$. En conjunto, la actuación arqueológica, dirigida por A. Domínguez Bolaños ${ }^{4}$, afectó a una zona de unos $95 \mathrm{~m}^{2}$ en la que se excavaron cerca de 120 sepulturas.

Las tres zonas en las que aparecen sepulturas se ubican en relación con la iglesia perrománica de nave única que está al $\mathrm{W}$ de la colegiata, un edificio de estilo románico en el que también se ha detectado una fase constructiva prerrománica. El principal conjunto es la zona del claustro, al $\mathrm{S}$ del templo, donde se han excavado 85 sepulturas, mientras que en la sala del claustro, al ENE del templo, han aparecido 15 sepulturas, y en la zona del antiguo cementerio 13 , al W del templo.

La orientación de las sepulturas es bastante homogénea en todos los casos, paralela a los muros del templo prerrománico, cuyo eje está ligeramente girado hacia el ENE y solo en algunas tumbas de lajas del claustro y de la sala del claustro se aprecia una disposición más exacta hacia el $\mathrm{E}$.

Cada una de las zonas presenta unas características diferentes, tanto por la complejidad de la secuencia estratigráfica como por la intensidad de uso del espacio, sin que se haya podido establecer una correlación precisa entre los niveles de las tres zonas.

En el claustro la secuencia es especialmente compleja. Según el informe de la excavación, se ha llegado a identificar hasta 15 niveles distintos de enterramientos. La reconstrucción más completa que hemos logrado elaborar a partir de los mismos datos ha sido de 11 episodios consecutivos, una muestra clara de la intensidad de uso que ha tenido este espacio. El volumen más importante de sepulturas corresponde a los momentos recientes, en el que se suceden decenas de inhumaciones en fosa simple que se superponen o destruyen las anteriores. En ocasiones los huesos de las sepulturas amortizadas se

3 Domínguez Bolaños, Alonso. «La documentación arqueológica de los edificios prerrománicos de San Martín de Elines». En Iglesias Gil, José Manuel (ed.). Cursos sobre el Patrimonio Histórico 7. Actas de los XIII Cursos Monográficos sobre el Patrimonio Histórico (Reinosa, julio-agosto 2002). Santander: Universidad de Cantabria, 2003, pp. 319-330.

4 Domínguez Bolaños, Alonso. Excavación arqueológica en San Martín de Elines. Valderredible (Cantabria). Ávila: 2004. Informe elaborado para el Servicio de Patrimonio Cultural de Cantabria, inédito. Agradecemos a A. Domínguez Bolaños la cesión del informe y de otros datos inéditos sobre la actuación arqueológica, así como de la documentación gráfica utilizada en este artículo. 
REIVINDICACIÓN DE ESTATUS Y COSTUMBRES FORÁNEAS EN EL REGISTRO FUNERARIO MEDIEVAL CASTELLANO. A PROPÓSITO DE DOS CASOS DE CANTABRIA

ENRIQUE GUTIÉRREZ CUENCA

recogen con cierto cuidado y se colocan sobre las nuevas, o al lado, como se aprecia en un caso donde aparece un esqueleto con restos de siete cráneos a sus pies. Excepcionalmente, aparecen algunas sepulturas con estructura perdurable en estos niveles superiores, como una tumba, construida con partes de sarcófagos y bloques, adosada al muro de la iglesia y superpuesta, al menos, a una sepultura en fosa simple. Debajo de las fosas simples aparecen tumbas de lajas, que se disponen en un único nivel. Aunque no hay superposiciones efectivas, hay evidencias claras de que las más recientes alteran y transforman algunas de las más antiguas. Una parte de estas tumbas de lajas, que en ocasiones se adosan unas a otras o muestran evidencias de haber sido reformadas, aparecen reutilizadas. La principal referencia cronológica de esta secuencia la ofrece una fosa simple, ubicada en mitad de la secuencia de la fase más reciente del cementerio, que rompe la base del sepulcro del «caballero peregrino" ${ }^{5}$, datado en 1231 . Debajo de la estructura que soporta el mencionado sepulcro se dispone una tumba de lajas, anterior por tanto al primer tercio del siglo xiII. Por otro lado, en la mayor parte de los casos en los que existe relación estratigráfica con el muro del claustro las sepulturas están afectadas por la construcción, pero hay al menos una fosa simple en la que la posición del cuerpo del difunto se adapta al citado muro, por lo que esa sepultura y quizá algunas más podrían ser posteriores a la construcción del claustro. Las dataciones radiocarbónicas ${ }^{6}$ en este sector determinan un lapso amplio de utilización, desde el siglo XIV para las sepulturas más recientes, hasta el siglo viI o incluso antes para las más antiguas.

La sala del claustro, por su parte, muestra una secuencia mucho más simple en la que únicamente se identifican cuatro o quizá cinco niveles superpuestos de sepulturas, lo que pone de manifiesto una utilización mucho menos intensa de este espacio. Según A. Domínguez Bolańos, esto puede ser debido a que era un espacio de enterramiento particular, reservado a un grupo familiar concreto. Los análisis de ADN realizados no aportaron datos que pudieran respaldar la interpretación. En los niveles superiores se alternan las inhumaciones en fosa simple con algunos ataúdes de madera, e inmediatamente por debajo hay dos niveles superpuestos de tumbas de lajas. Entre ambos niveles de tumbas de lajas se observan diferencias constructivas y en el uso, ya que las del nivel superior están construidas a partir de materiales reaprovechados -elementos constructivos y fragmentos de sarcófago- y, al menos en un caso, conservan restos de más de un individuo. Precisamente el uso de material constructivo ofrece una referencia cronológica

5 Se trata de un sarcófago gótico con decoración figurada, representaciones heráldicas, motivos ornamentales en la cubierta e inscripción que lo fecha en 1231, colocado sobre sendos soportes con figuraciones de perros. La representación de una espada y una venera en la cubierta han dado lugar a la creencia de que el sarcófago servía de sepultura a un caballero que había peregrinado a Santiago de Compostela. Un estudio reciente ha demostrado que la venera es un emblema heráldico, relacionado con la Orden de Santiago. Rivero Sierra, Borja. «La heráldica del sepulcro del caballero de San Martín de Elines». ASCAGEN. Revista de la Asociación Cántabra de Genealogía, 2013, vol. 9, pp. 11-32.

6 Los resultados de las dataciones absolutas fueron recibidos con posterioridad a la entrega del informe de la actuación arqueológica y permanecen inéditos. A. Domínguez Bolaños, director de la excavación, nos ha proporcionado amablemente algunos detalles sobre la orientación cronológica que ofrecen dichas dataciones, pero no nos ha facilitado ni los resultados completos de los análisis, ni la procedencia concreta de cada una de las muestras. Las referencias a dichas dataciones en este texto son, por lo tanto, incompletas e imprecisas y como tales deben entenderse. 
REIVINDICACIÓN DE ESTATUS Y COSTUMBRES FORÁNEAS EN EL REGISTRO FUNERARIO MEDIEVAL CASTELLANO. A PROPÓSITO DE DOS CASOS DE CANTABRIA ENRIQUE GUTIÉRREZ CUENCA

para la secuencia, ya que dos de las tumbas de lajas más recientes utilizan como cubierta cornisas románicas decoradas con billetes, lo que estaría indicando una datación posterior a comienzos del siglo XII. La fase más reciente se puede datar gracias a los restos de ataúdes de madera con tachuelas ornamentales y a la aparición de un par de acicates en los pies de la sepultura UE 67, ambos elementos fechables en torno a los siglos XIII-XIV por su similitud con elementos similares del Panteón Real de Las Huelgas (Burgos) ${ }^{7}$. No obstante, las dataciones radiocarbónicas obtenidas no concuerdan con algunos de estos datos, ya que se remontan a un periodo entre mediados del siglo ix y mediados del siglo $\mathrm{x}$ y sitúan una sepultura superpuesta a las cornisas de estilo románico en torno a 960.

El conjunto excavado en la zona del antiguo cementerio, junto a los pies de la iglesia prerrománica, también presenta una estratigrafía más sencilla que la del claustro, con un máximo de cuatro niveles de sepulturas en fosa simple superpuestas entre sí y colocadas por encima de un único nivel de tumbas de lajas. Como sucede en las otras zonas, es frecuente que las fosas más recientes destruyan sepulturas anteriores. La cronología de este conjunto es imprecisa, ya que únicamente se dispone de una datación de $\mathrm{C}^{14}$ para una de las tumbas de lajas de la base de la estratigrafía, fechada en torno a mediados del siglo viI y no existen otras referencias directas para las sepulturas más recientes.

Por lo que respecta a la tipología de los contenedores utilizados en las sepulturas, se ha podido determinar con precisión en 113 casos. Corresponden mayoritariamente a sepulturas de fosa simple, que representan el $73 \%$ del total, seguidas por un $17 \%$ de tumbas de lajas, un $5 \%$ de ataúdes de madera y otro $5 \%$ de tipología diversa, desde sarcófagos reaprovechados a estructuras formadas por grandes bloques. Los diferentes tipos aparecen en distintos momentos de uso, como ya se ha sugerido, correspondiendo por lo general las sepulturas en fosa simple a las etapas más antiguas y más recientes de uso del espacio cementerial y las tumbas de lajas a momentos alto y plenomedievales.

Los contenedores más interesantes, por su relación con las sepulturas en las que aparecen los acicates a los que se refiere este trabajo, son los ataúdes de madera decorados con tachuelas. Aparecían muy alterados e incluso algunas piezas desplazadas de su posición original, pero lo más probable es que fuesen utilizados en las sepulturas UE 142, 141 y 67 de la sala del claustro -en el último caso, un fragmento se reaprovecha como cubierta sobre una sepultura infantil inmediatamente superior-y en la UE 187 del claustro. Se conservan unos 90 fragmentos de madera tachuelada de diversos tamaños y la buena conservación del material lígneo ha permitido determinar que se construyeron con tableros de pino ${ }^{8}$. Las tachuelas son de plata aleada con cobre, con la cabeza redondeada y aplanada o ligeramente cónica. En algunos casos las tachuelas fijan a la madera cintas de trencilla de hilo de cobre entorchado de oro. El fragmento más completo permite reconstruir un motivo en forma de cruz. Este tipo de ataúdes son muy similares a varios ejemplares conservados en las tumbas

7 Gómez Moreno, Manuel. El Panteón Real de las Huelgas de Burgos. Madrid: Consejo Superior de Investigaciones Científicas, 1946.

8 Rodríguez Rodríguez, Adelaida. Memoria del tratamiento de conservación y restauración aplicado a acicates y fragmentos de ataúdes procedentes de la ex colegiata de San Martín de Elines, Valle de Valderredible, Cantabria. Burgos: 2002. Informe inédito, consultado en el archivo del Museo de Prehistoria y Arqueología de Cantabria. 
REIVINDICACIÓN DE ESTATUS Y COSTUMBRES FORÁNEAS EN EL REGISTRO FUNERARIO MEDIEVAL CASTELLANO. A PROPÓSITO DE DOS CASOS DE CANTABRIA ENRIQUE GUTIÉRREZ CUENCA

reales del panteón de Santa María la Real de Las Huelgas (Burgos), como los de Enrique I $(\dagger 1217)$, Fernando de Navarra ( $† 1208)$ y, sobre todo, el de Blanca de Portugal ( $\dagger 1321)$, o los atribuidos a Sancho $\left(\dagger 1343\right.$ ) y a un personaje sin identificar ${ }^{9}$, con un patrón decorativo muy similar al que muestran los de San Martín de Elines. Dos de los individuos asociados a este tipo de ataúdes (UE 67 y UE 187) llevaban colocados sendos pares de acicates sobredorados que describimos más abajo.

El estudio antropológico, realizado por un equipo de la Universidad de León dirigido por J. F. Pastor Vázquez ${ }^{10}$, identificó los restos de un mínimo de 125 individuos. Hay individuos de ambos sexos y de todas las categorías de edad, aunque sí se observaron algunos datos relevantes que conviene reseñar. Por un lado, en los adultos hay un desequilibrio evidente entre sexos, con una proporción de individuos de sexo femenino que ronda el $40 \%$. Por otro lado, y quizá en relación con lo anterior, el número de individuos infantiles es bajo, en torno al $16 \%$, aunque, si se toman como referencia los inmaduros, la tasa se acerca al $20 \%$, un valor mucho más próximo a lo habitual en otras colecciones. El equipo que realizó el estudio relaciona estos valores con «consideraciones sociales». La baja presencia de mujeres y niños podría estar reflejando una sobrerrepresentación de los varones adultos pertenecientes a la comunidad monástica, usuarios preferentes del espacio cementerial. El estudio llama la atención también sobre tres individuos con heridas peri-mortem provocadas por filos cortantes.

La propuesta de interpretación cronológica y de evolución del cementerio que se recogía en el informe de la excavación planteaba un lapso de utilización entre los siglos $\mathrm{x}$ y XVI en el que se sucedían diferentes fases. En la más antigua, hasta mediados del siglo XII, se utilizaban las tumbas de lajas de forma individual. Entre mediados del siglo XII y el siglo XIII las tumbas de lajas pasarían a ser sepulturas colectivas. En un momento inmediatamente posterior se hacen habituales las sepulturas en fosa simple y aparecen los escasos ataúdes de madera documentados, mientras que en la fase más reciente conviven fosas simples de uso individual y de uso colectivo con algunas estructuras construidas con bloques de piedra. El marco cronológico ha sido corregido con posterioridad por las dataciones radiocarbónicas, situándose el uso del cementerio entre los siglos VI-VIII y el siglo $\mathrm{XIV}^{11}$. Con respecto del modelo de evolución del cementerio, quizá lo más discutible es el concepto de "sepulturas colectivas» y la sucesión propuesta en el caso de las tumbas de lajas, ya que parece más bien que a lo largo del periodo de uso de este tipo de contenedores se van alternando ambas formas de gestionar las tumbas, sin que la variación se pueda relacionar con una cuestión cronológica. Las alteraciones que sufren algunas de las tumbas de lajas parece consecuencia de la utilización intensiva del espacio que se generaliza en los momentos pleno y bajomedievales, cuando se hacen frecuentes las sepulturas en fosa simple. Las dataciones absolutas sugieren, además, que no en todas las zonas se empieza a enterrar al mismo tiempo. Al S y al W de la iglesia prerrománica

9 Gómez Moreno, El Panteón Real de las Huelgas, láms. XXXVII, XLIV, XLVI y XLIX. Pese a la similitud formal, la cronología de estos dos últimos ejemplos es algo tardía en relación con la que proponemos para los ataúdes de San Martín de Elines.

10 Domínguez Bolaños, Excavación arqueológica en San Martín de Elines, pp. 211-215.

11 Domínguez Bolaños, Alonso, comunicación personal. 
REIVINDICACIÓN DE ESTATUS Y COSTUMBRES FORÁNEAS EN EL REGISTRO FUNERARIO MEDIEVAL CASTELLANO. A PROPÓSITO DE DOS CASOS DE CANTABRIA ENRIQUE GUTIÉRREZ CUENCA

hay sepulturas que se remontan al siglo VII, mientras que en la zona E la secuencia puede que no vaya más allá del siglo IX.

Entre los objetos que acompañan a los restos humanos, cuya presencia es muy poco frecuente, destaca el hallazgo ya mencionado de tres pares de acicates de hierro sobredorado, que han sido recuperados gracias al trabajo de restauración de A. Rodríguez Rodríguez. Dos de ellos fueron localizados en su posición original, a los pies de sendas «sepulturas de caballero», mientras que del tercero no se conoce la procedencia exacta.

De los dos acicates de la UE 67 se conserva uno casi entero y un fragmento de la rama del otro que no ha permitido su reconstrucción. El mejor conservado tiene la caja curva y la espiga de sección circular inclinada $45^{\circ}$ respecto a la caja, con botón circular aplanado y punta corta. No conserva el remate de las ramas. Son de hierro, chapado con plata sobredorada. Tienen una longitud rama de $105 \mathrm{~mm}$ y una longitud espiga de $65 \mathrm{~mm}$, mientras que el botón tiene $25 \mathrm{~mm}$ de diámetro y la punta $17 \mathrm{~mm}$. La sepultura apareció en la sala del claustro y corresponde a un individuo adulto de entre 30 y 60 años del que no se ha podido determinar el sexo. Posiblemente empleaba un ataúd de madera decorado con tachuelas de plata y cobre. Los acicates estaban colocados en los pies del individuo (Fig. 1).

De los dos acicates de la UE 187, uno está prácticamente completo y del que no se conservan los brazos y ha sido reconstruido. Tienen la caja curva y la espiga de sección circular inclinada $45^{\circ}$ respecto a la caja, con botón circular aplanado y punta corta. La rama exterior está rematada con una argolla a la que se sujeta una placa para fijar la correa y un broche de placa rígida. La rama interior está rematada con un pasador rectangular para las correas. Son de hierro chapado con plata sobredorada y tienen restos de tejido adheridos en algunas zonas. El acicate izquierdo, el más completo, conserva el broche y parte de la placa en el brazo exterior (Fig. 2), pero no el remate del brazo interior. La rama tiene una longitud de $110 \mathrm{~mm}$ y la espiga $72 \mathrm{~mm}$. El botón tiene $22 \mathrm{~mm}$ de diámetro y la punta $17 \mathrm{~mm}$ de longitud. El broche es de hebilla oval con remate plano y hebijón de hierro, unida a una placa de cobre dorado que está decorada con roleos vegetales y tiene dos remaches de cobre aleado para fijar a la correa. La placa, fragmentada, es también de cobre dorado. El acicate derecho no conserva ningún brazo completo, pero sí parte del pasador rectangular del brazo interior. Aparecieron además, fuera de su posición original, el broche, con hebilla oval de remate plano unida a una placa de cobre dorado decorada con roleos vegetales y con sus remaches de punta cónica y hebijón de hierro, y una placa de cobre dorado decorada con roleos vegetales, un remache cónico y el orificio para otro, perdido. Proceden de la panda $\mathrm{N}$ del claustro, de una sepultura prácticamente destruida en la que apenas quedaban huesos en su posición original, sin que se haya podido determinar ni el sexo ni la edad del individuo, solo se sabe que se trata de un adulto. Restos de madera y tachuelas y las marcas verdes sobre los huesos conservados permiten suponer que estaba enterrado en un ataúd de madera decorado con tachuelas de plata y cobre.

En la UE 44, un nivel entre sepulturas de la sala del claustro, aparecieron otros dos ejemplares de acicates, uno prácticamente completo y otro del que no se conservan 
REIVINDICACIÓN DE ESTATUS Y COSTUMBRES FORÁNEAS EN EL REGISTRO FUNERARIO

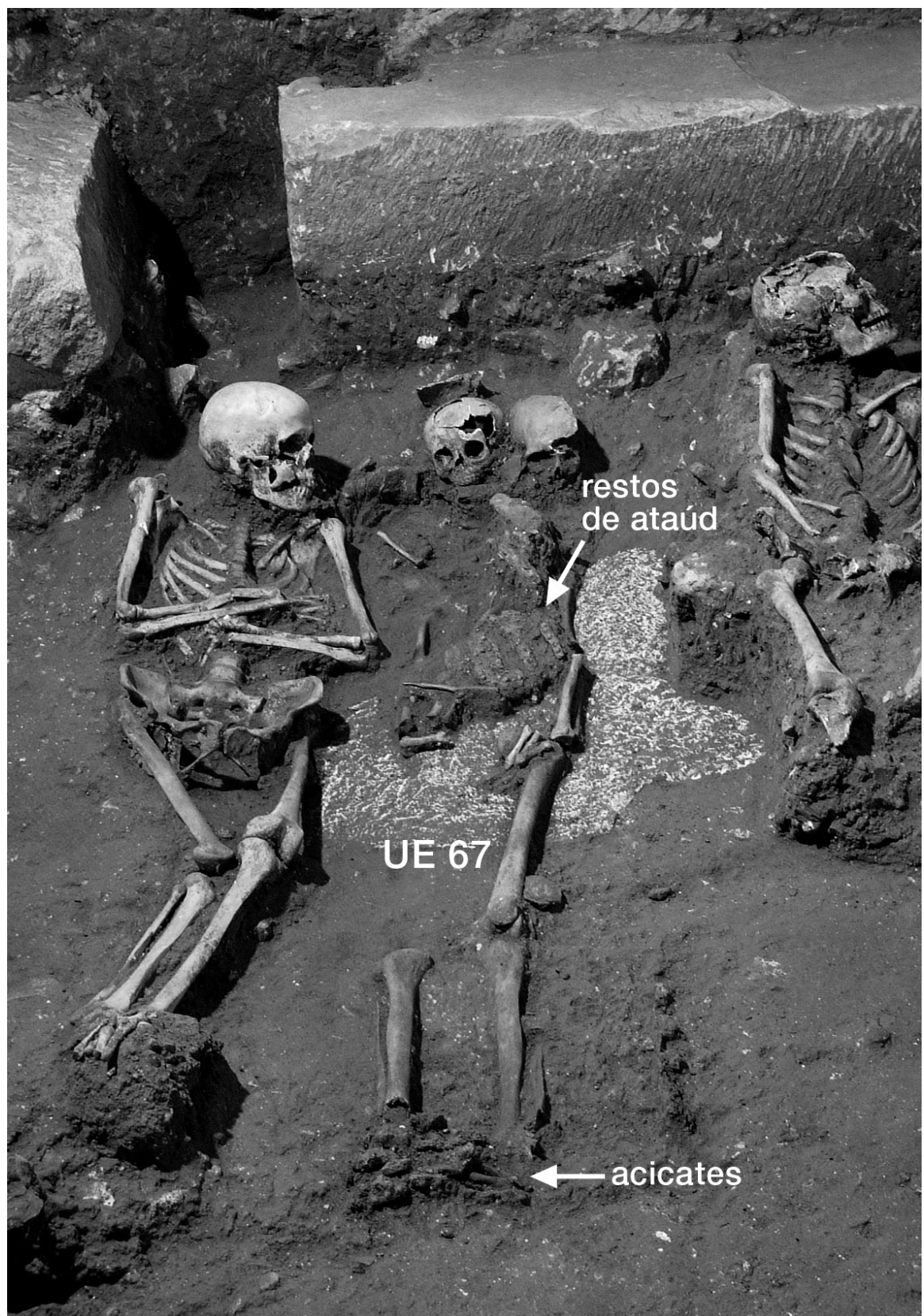

FIG. 1. Sepultura UE 67 de la sala del claustro de San Martín de Elines con restos de ataúd decorado y acicates colocados en los pies. Foto: A. Domínguez Bolańos (Archeos S. L.). 
REIVINDICACIÓN DE ESTATUS Y COSTUMBRES FORÁNEAS EN EL REGISTRO FUNERARIO MEDIEVAL CASTELLANO. A PROPÓSITO DE DOS CASOS DE CANTABRIA

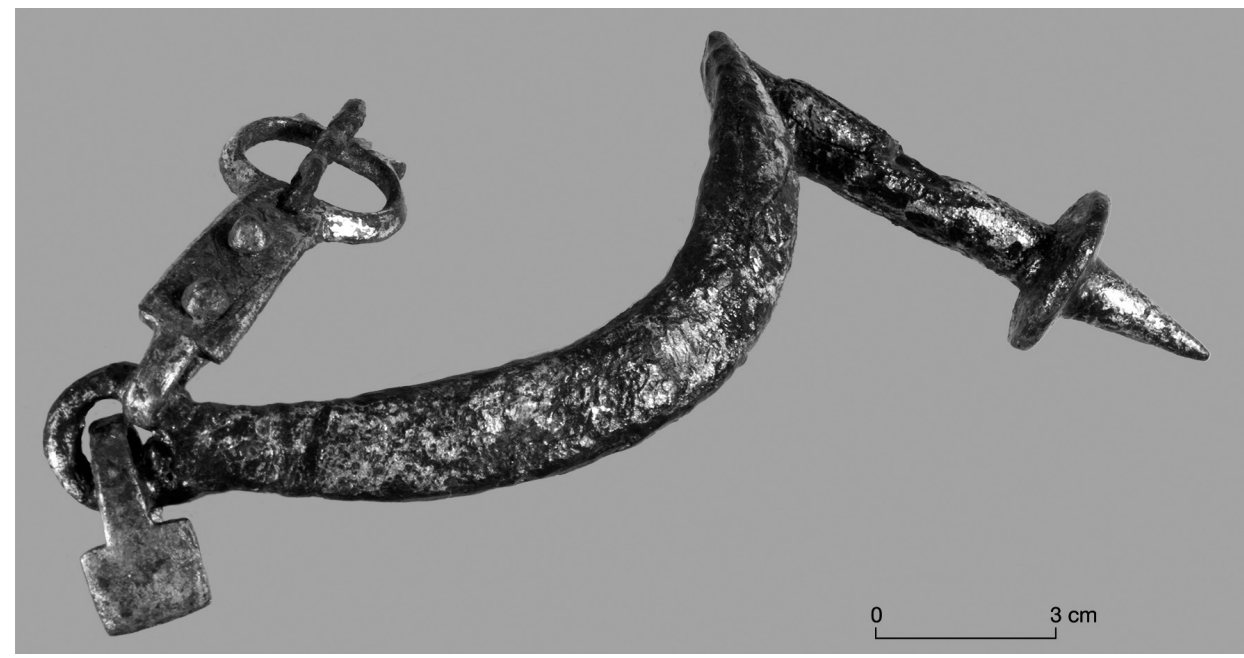

Fig. 2. Acicate de hierro, chapado en plata sobredorada, de la UE 187 de San Martín de Elines. Foto: autor.

los brazos y ha sido reconstruido ${ }^{12}$. Tienen la caja curva y la espiga de sección circular inclinada $45^{\circ}$ respecto a la caja, con botón esférico y punta larga. La rama exterior está rematada con una argolla a la que se sujeta una placa para fijar la correa y un broche de placa rígida (Fig. 3). La rama interior termina en un pasador rectangular para las correas.

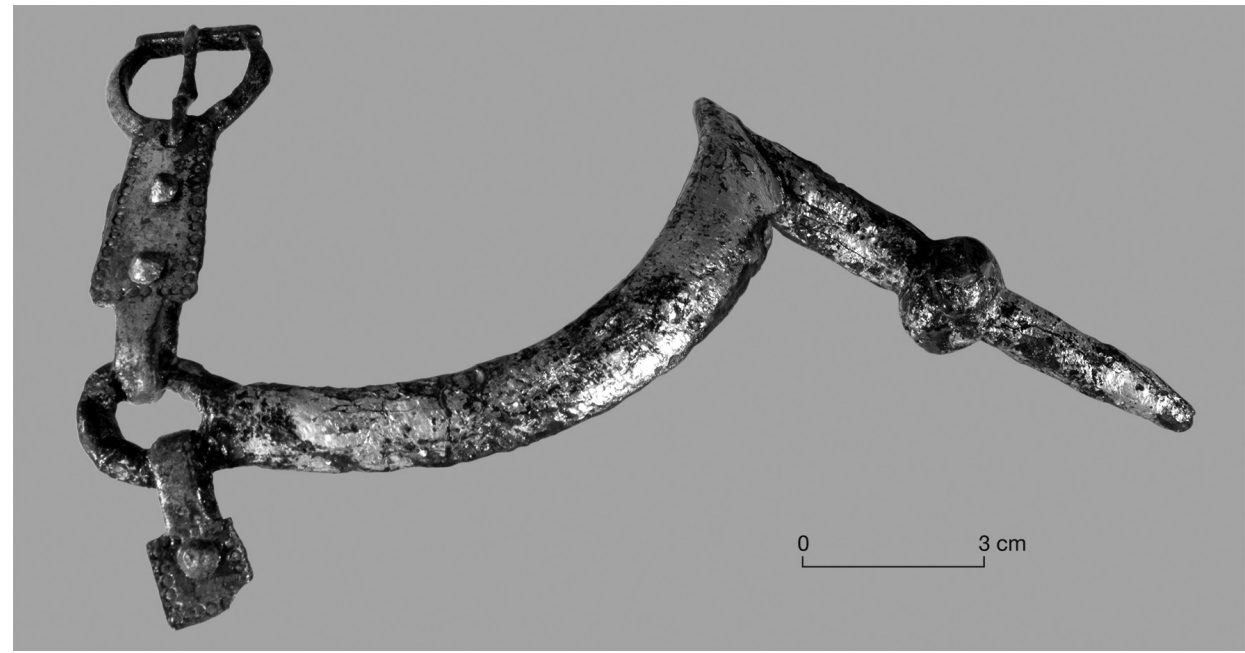

FIG. 3. Acicate de hierro, chapado en plata sobredorada, de la UE 44 de San Martín de Elines. Foto: autor.

12 Es el único par de acicates de San Martín de Elines que ha sido recogido en una publicación. Rodríguez Rodríguez, Adelaida. «Acicates». En Elorza Guinea, Juan Carlos (ed.). El Cid, del hombre a la leyenda. Valladolid: Junta de Castilla y León, 2007, p. 221. 
REIVINDICACIÓN DE ESTATUS Y COSTUMBRES FORÁNEAS EN EL REGISTRO FUNERARIO MEDIEVAL CASTELLANO. A PROPÓSITO DE DOS CASOS DE CANTABRIA

ENRIQUE GUTIÉRREZ CUENCA

Son de hierro revestido con plata dorada. La rama tiene $123 \mathrm{~mm}$ de longitud y la espiga $82 \mathrm{~mm}$. El diámetro del botón es de $17 \mathrm{~mm}$ y la punta tiene entre 31 y $35 \mathrm{~mm}$ de longitud. El acicate izquierdo conserva el broche y la placa en el brazo exterior, mientras que en el brazo interior conserva solo parte del remate rectangular. El broche, con hebilla oval de remate plano unida a una placa de cobre dorado decorada con líneas de círculos incisos y con dos remaches de cobre aleado para fijar a la correa, y hebijón de hierro. La placa, de cobre dorado, es cuadrada, está también decorada con líneas de círculos incisos y lleva un remache. El acicate derecho conserva también el broche y la placa del lado exterior, pero nada del remate del interior. El broche, con hebilla oval de remate plano, fracturada, unida a una placa de cobre dorado decorada con líneas de círculos incisos y con dos remaches de cobre aleado para fijar a la correa, y hebijón de hierro. La placa, de cobre dorado, es cuadrada, está también decorada con líneas de círculos incisos y lleva un remache. Se conservan otros elementos metálicos de sujeción del correaje fuera de su posición original: dos placas de cobre dorado decoradas con roleos vegetales y con dos remaches cónicos en los extremos, y dos placas de cobre dorado decoradas con líneas de puntos incisos y con dos remaches en los extremos. Este par de acicates apareció sin relación directa con ninguna sepultura.

La morfología de los tres pares de acicates es similar (Fig. 4), con caja a 45º, botón esférico o aplanado y punta cónica más o menos desarrollada. Lo mismo sucede con las piezas de sujección, con hebillas ovales y placas decoradas con roleos. El par de la UE 44 presenta características formales que podrían considerarse algo más arcaicas, con el botón esférico y la punta más larga. La cronología, en todos los casos, se puede fijar en el siglo XIII, atendiendo a los paralelos existentes en la península Ibérica ${ }^{13}$, sin olvidar que no hay ningún ejemplo de este modelo con una datación fiable más allá de criterios tipológicos.

Por extensión, a falta de otros criterios para determinar con precisión la fecha de las sepulturas de San Martín de Elines en las que aparecen los acicates, la tipología de los mismos son el mejor indicador para situarlas en algún momento del siglo XIII. No aparecen otros elementos que tengan que ver con el atuendo, por lo que no podemos afirmar con seguridad que estos individuos hayan sido enterrados vestidos, quizá estaban envueltos en un sudario y los acicates eran el único distintivo de su condición de caballeros que portaban ${ }^{14}$. La interpretación planteada en su momento por A. Domínguez Bolaños es que se trata de sepulturas de "caballeros villanos»" ${ }^{15}$, caballería de segundo orden y de origen local, pero con cierta preeminencia sobre el pueblo llano. No obstante, conviene señalar que esa caballería villana tenía limitaciones en su atuendo y no le estaba permitido

13 García Álvarez-Busto, Alejandro y Fernández Calderón, Noelia. «El caballero de las espuelas doradas. Análisis arqueológico de un enterramiento nobiliario medieval del monasterio de Corias». Gladius, 2014, vol. 34, pp. 135-152.

14 Tenemos constancia segura de que los individuos que portan acicates fueron enterrados vestidos en las tumbas reales de Las Huelgas. Gómez Moreno, El Panteón Real de las Huelgas. También hay algún indicio que señala la presencia de otros elementos de atuendo, como el cuero de las botas aparecido asociado a unos acicates en una tumba del monasterio de Corias (Asturias). García Álvarez-Busto, Alejandro. "La topografía funeraria del monasterio de Corias en la época medieval a partir de la arqueología y las fuentes escritas». Territorio, Sociedad y Poder. Revista de Estudios Medievales, 2012, vol. 7, pp. 129-178.

15 Domínguez Bolaños, Excavación arqueológica en San Martín de Elines, p. 185. 
REIVINDICACIÓN DE ESTATUS Y COSTUMBRES FORÁNEAS EN EL REGISTRO FUNERARIO MEDIEVAL CASTELLANO. A PROPÓSITO DE DOS CASOS DE CANTABRIA ENRIQUE GUTIÉRREZ CUENCA
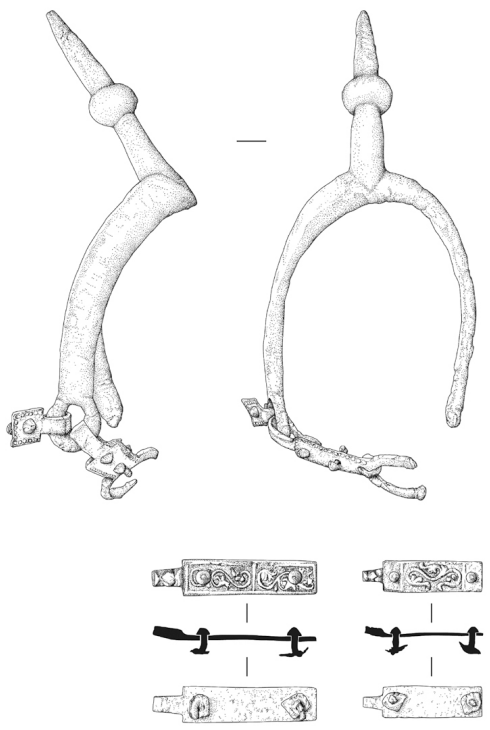

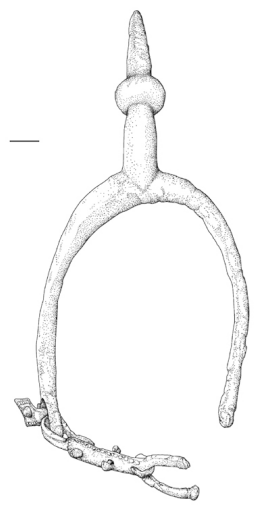

9 (a)
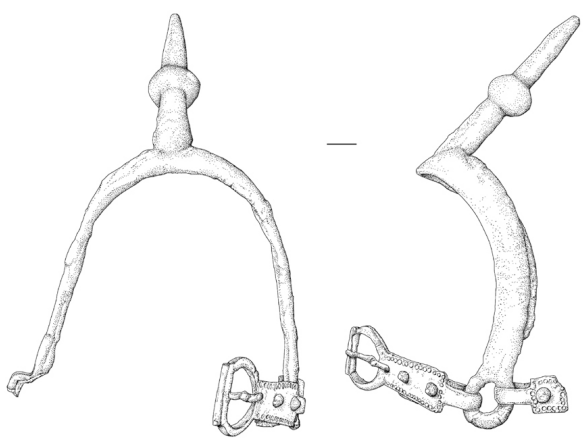

UE 44
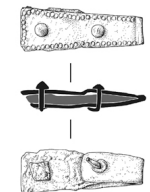
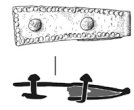

(2)

UE 44
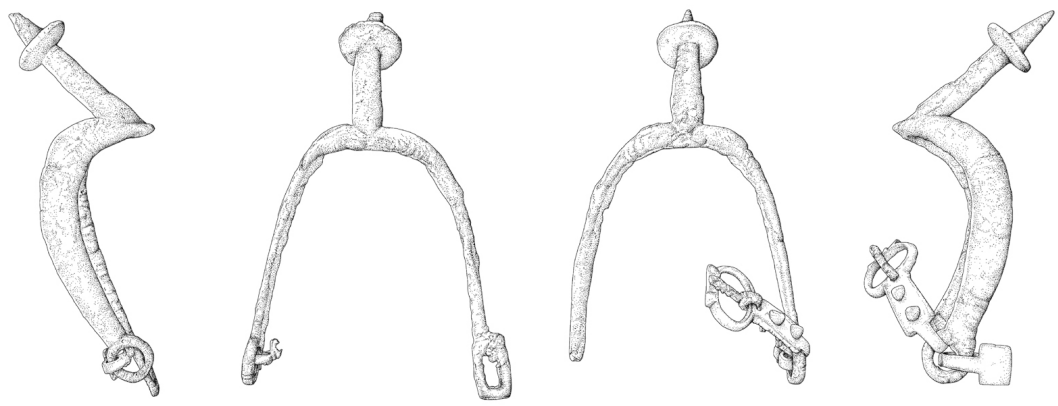

UE 187
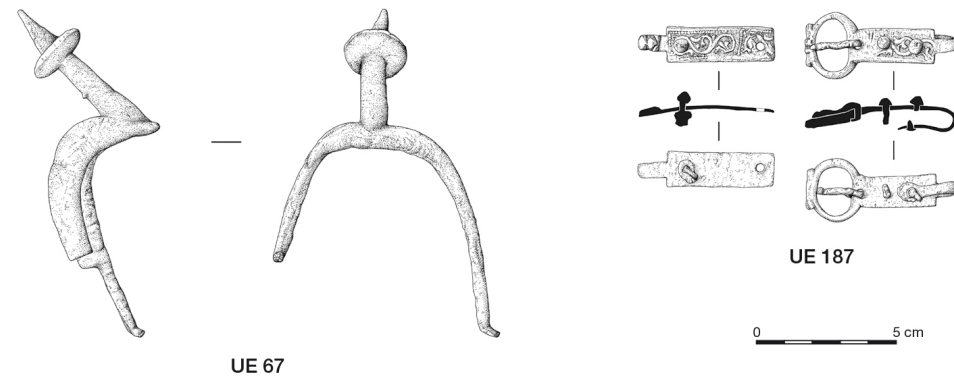

FIg. 4. Acicates de San Martín de Elines. Dibujo: autor. 
REIVINDICACIÓN DE ESTATUS Y COSTUMBRES FORÁNEAS EN EL REGISTRO FUNERARIO MEDIEVAL CASTELLANO. A PROPÓSITO DE DOS CASOS DE CANTABRIA

ENRIQUE GUTIÉRREZ CUENCA

usar determinados elementos reservados a los caballeros de linaje. Entre los complementos vetados estaban las «espuelas doradas», reservadas a los nobles que habían obtenido esa merced por concesión regia o como parte de la investidura, como se deduce del hecho de que las Cortes de Burgos de 1379 concediesen una gracia especial al permitir usar estos y otros distintivos dorados a los llamados caballeros «de la gineta del Andaluzia»"

A esta consideración general habría que unir el hecho particular de que San Martín de Elines contaba en el siglo xiI con el patrocinio de la más alta nobleza castellana. Tenemos constancia documental de esta circunstancia a finales del siglo XIII, cuando figuran como patronos del monasterio los hermanos Lope Rodríguez de Villalobos y Roy Gil, junto con Garci Fernández Manrique de Lara ${ }^{17}$. Es probable que las sepulturas de caballero con acicates y ataúdes ricamente decorados pertenezcan a nobles de este mismo linaje que ostentaba el señorío de San Martín de Elines. Estos personajes elijen en algún momento a partir de terciado el siglo XIII ese centro religioso como lugar de sepultura, siguiendo una tendencia observada en esta época para los enterramientos nobiliarios ${ }^{18}$, y que ya en 1231 estaría atestiguado con el sarcófago del "caballero peregrino», atribuido a Rodrigo Pérez Manrique ${ }^{19}$, señor del lugar y merino mayor de Castilla, cuyo linaje se hace entroncar con Rodrigo Díaz de Vivar, el Cid.

\section{LaS «espuelas doradas» COMO Distintivo de estatus en Castilla}

La presencia de acicates y espuelas en contextos funerarios a partir del siglo XII y especialmente en el siglo XIII está atestiguada en diferentes puntos de la Península Ibérica, aunque no es demasiado frecuente. Su distribución geográfica se centra sobre todo en el tercio norte peninsular, en territorios del reino de Castilla, aunque también se conocen casos en los reinos de Navarra y Portugal (Mapa 1).

Tenemos noticia de hallazgos de acicates «dorados», similares a los de San Martín de Elines -del tipo de remate en punta, de tradición andalusí-, tanto en sepulturas localizadas en cementerios y sin ningún elemento externo que las diferencie del resto, como en enterramientos privilegiados ubicados en espacios interiores de edificios religiosos. En el primer supuesto podemos citar el par de espuelas de la inhumación 64 de San Prudencio de Armentia (Álava) ${ }^{20}$, posiblemente algo más antiguas que las de San Martín de Elines;

16 Martínez Martínez, María y Lora Serrano, Gloria. «Las inversiones suntuarias de la nobleza a fines de la Edad Media». En Vilar, Juan Bautista; Peñafiel Ramón, Antonio e Irigoyen López, Antonio (eds.). Historia y sociabilidad: homenaje a la profesora Maria del Carmen Melendreras Gimeno. Murcia: Universidad de Murcia, 2007, pp. 197-222.

17 Pereda Llarena, Francisco Javier. Documentación de la Catedral de Burgos (1254-1293). Burgos: Catedral de Burgos, 1984, docs. 322 y 325.

18 Serrano Coll, Marta. «Espacios monásticos como locus sepulturae: enterramientos nobiliarios en el románico hispano». En García de Cortázar, José Ángel y Teja, Ramón (eds.). Monasterios y nobles en la España del románico: entre la devoción y la estrategia. Aguilar de Campoo: Fundación Santa María la Real, 2014, pp. 137-175.

19 Rivero Sierra, «La heráldica del sepulcro del caballero de San Martín de Elines».

20 López Sebastián, Paloma. «Espuelas doradas de Armentia». Akobe, 2008, vol. 9, pp. 34-38. 


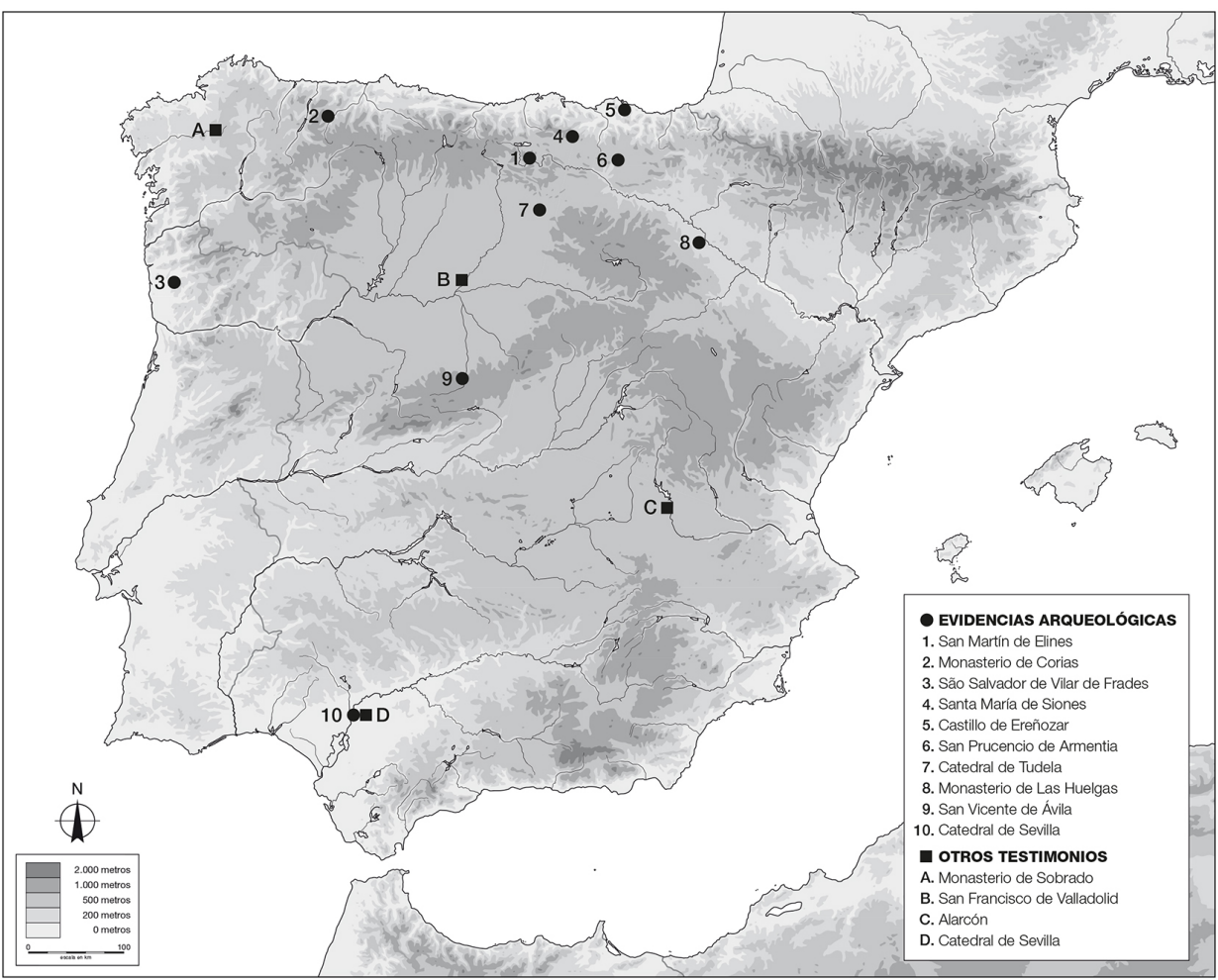

MAPA 1. Distribución de los acicates procedentes de «sepulturas de caballero» en la península Ibérica. Mapa: autor.

el ejemplar aparecido en Santa María de Siones (Burgos), ya del siglo XIII' ${ }^{21}$; el acicate del enterramiento 77 de Ereńozar (Vizcaya) ${ }^{22}$. Fuera de su contexto original, aunque procedentes de una necrópolis arrasada por la construcción del edificio, aparecieron cuatro acicates de hierro sin sobredorado en São Salvador de Vilar de Frades (Portugal) ${ }^{23}$. Asociados a sepulturas privilegiadas encontramos un caso en el monasterio de Corias (Asturias), en un enterramiento realizado dentro de la iglesia convertida en capilla funeraria en torno al siglo XIII ${ }^{24}$; otro en el sepulcro de los Estrada de la iglesia de San Vicente

21 Soler del Campo, Álvaro. «Acicate». En Zozaya, Juan (ed.). Alarcos. El fiel de la balanza. Toledo: Junta de Comunidades de Castilla-La Mancha, 1995, p. 197.

22 Neira Zubieta, Mikel. «Estudio de los objetos metálicos y pétreos», en prensa. En este mismo yacimiento, en un contexto de abandono y derribo del castillo, apareció otro ejemplar de acicate similar, aunque en este caso sin baño sobredorado.

23 Cortés, Ricardo Erasun y Faure, Francisco Líbano. «Um conjunto de esporas medievais provenientes do convento de S. Salvador de Vilar de Frades (Barcelos)». Portugalia, 2008-2009, vol. 29-30, pp. 179-192.

24 García Álvarez-Busto, «La topografía funeraria del monasterio de Corias en la época medieval». 
REIVINDICACIÓN DE ESTATUS Y COSTUMBRES FORÁNEAS EN EL REGISTRO FUNERARIO MEDIEVAL CASTELLANO. A PROPÓSITO DE DOS CASOS DE CANTABRIA

de Ávila ${ }^{25}$; un par en la sacristía del Espíritu Santo de la catedral de Tudela (Navarra) ${ }^{26}$; el par de acicates del sepulcro de Fernando de la Cerda († 1275), en el panteón real de Las Huelgas (Burgos) ${ }^{27}$; y el par de Fernando III el Santo ( $\left.† 1252\right)$, procedentes de su sepultura en la catedral de Sevilla ${ }^{28}$.

En el siglo xIv los acicates serán sustituidos por un nuevo modelo, las espuelas de rueda, que seguirán apareciendo en algunos contextos funerarios. Los ejemplares más relevantes proceden de Navarra. Dos pares aparecieron en la capilla de San Martín de la catedral de Tudela, en las sepulturas superpuestas de Juan Renalt de Ujué († 1392) y su hijo, cuyos cuerpos estaban también acompañados por la espada y la hebilla del $\operatorname{cinto}^{29}$ y otro par procede de la sepultura 17 de la sacristía del Espíritu Santo de la catedral de Tudela ${ }^{30}$.

Además de estos ejemplos documentados a través de la Arqueología, disponemos de varias referencias transmitidas por fuentes del siglo XvII acerca de la presencia de «espuelas doradas» en sepulturas medievales. Se refieren en todos los casos a sepulturas privilegiadas, ubicadas en el interior de edificios religiosos. N. R. Porro Girardi se hace eco de dos noticias de este tipo, en momentos bastante tempranos: una referida a la sepultura de Fernán Martínez de Ceballos († c 1212) en Alarcón (Cuenca) y otra a la sepultura de Juan Mathe de Luna († 1209) en Sevilla ${ }^{31}$. Otra noticia de este tipo deja constancia de un caballero enterrado seguramente a principios del siglo XV con espuelas, espada y la banda de la Orden de la Banda, cuyo cuerpo fue hallado así ataviado al reformar una capilla en el convento de San Francisco de Valladolid en $1623^{32}$. A estos testimonios habría que añadir la sepultura del caballero Pedro Fernández de Castro († 1342) en el monasterio de Sobrado, ya que su primer testamento, al que nos referiremos a continuación, deja constancia de que fue enterrado portando espuelas y espada ${ }^{33}$.

25 Jiménez GadeA, Javier. «Acicate». En Jiménez Gadea, Javier; Echevarría Arsuaga, Ana; TApia Sánchez, Serafín y Villanueva Zubizarreta, Olatz (eds.). La memoria de Alá. Mudéjares y moriscos de Ávila. Valladolid: Castilla Ediciones, 2011,pp. 48-49.

26 Sesma Sesma, Jesús. «Acicates y espuelas de la sacristía del Espíritu Santo. Catedral de Tudela». En Caballeros y caballos entre 1212 y 1512. Pamplona: Museo de Navarra, 2012, pp. 38-39.

27 Gómez Moreno, El Panteón Real de las Huelgas, p. 22.

28 Soler del Campo, Álvaro. «Acicates (espuelas) del rey Fernando III el Santo». En Metrópolis Totivs Hispaniae. Sevilla: Ayuntamiento de Sevilla, 1999, p. 236.

29 Sesma Sesma, Jesús. «Ajuar funerario de Juan Renalt de Ujué, padre e hijo». En Caballeros y caballos entre 1212 y 1512, pp. 34-37.

30 Sesma SeSma, "Acicates y espuelas de la sacristía del Espíritu Santo ». Hay un cuarto par de espuelas de rueda en Navarra, procedente de Andosilla, pero se desconoce el contexto del hallazgo. Redín ArmañanZAs, Ana. «Espuelas de Andosilla». En Caballeros y caballos entre 1212 y 1512, pp. 40-41.

31 Porro Girardi, Nelly Raquel. La investidura de armas en Castilla: del rey Sabio a los Católicos. Valladolid: Junta de Castilla y León, 1998, p. 204. La noticia referida a Alarcón la recoge Juan Pablo Mártir Rizo en su obra Historia de la muy noble y leal ciudad de Cuenca. Madrid: por los herederos de la viuda de P. ${ }^{\circ}$ de Madrigal, 1629; y la de Sevilla Pablo Espinosa de los Monteros en su Teatro de la santa iglesia metropolitana de Sevilla. Sevilla: por Matías Clauijo, 1635.

32 Martínez Aguado, Inmaculada. «Un retablo para el convento de San Francisco de Valladolid del pintor Manuel Mateo». Boletín del Seminario de Estudios de Arte y Arqueología, 1999, vol. 65, pp. 335-342. La noticia la recoge Matías de Sobremonte en Noticias chronographicas y topographicas del Real y religiosísimo convento de los frailes menores observantes de S. Francisco de Valladolid, manuscrito de 1660.

33 Portela Silva, Ermelindo y Méndez Pallares, María Carmen. «Los espacios de la muerte». En La idea y el sentimiento de la muerte en la historia y en el arte de la Edad Media (II). Santiago de Compostela: 
REIVINDICACIÓN DE ESTATUS Y COSTUMBRES FORÁNEAS EN EL REGISTRO FUNERARIO MEDIEVAL CASTELLANO. A PROPÓSITO DE DOS CASOS DE CANTABRIA ENRIQUE GUTIÉRREZ CUENCA

En un primer momento, nos planteamos que la presencia de este tipo de ornamentos caballerescos en las sepulturas sea consecuencia de la imitación por parte de la nobleza de costumbres funerarias que en origen estaban reservadas a la realeza y la más prominente aristocracia de los reinos cristianos ${ }^{34}$. Más teniendo en cuenta que en San Martín de Elines aparecen asociados a un tipo de ataúd rico del que únicamente tenemos constancia, por el momento, en sepulturas regias. Sin embargo, un análisis más detenido del momento en el que se produce este tipo de manifestaciones nos ha hecho plantearnos que el uso de espuelas y otros elementos en el atuendo funerario va más allá de una simple ostentación mimética y está ligada al proceso de configuración de la orden de caballería en Castilla como elemento de diferenciación social de la nobleza de sangre afín a la corona a partir del siglo XIII.

Sobre el valor de representación de los acicates y otros elementos empleados en la investidura como elemento propio y definitorio del caballero, específicamente en el ámbito funerario, nos habla con elocuencia el primer testamento de Pedro Fernández de Castro en 1337, en el que especificaba que le colocasen cuando muriese una espada y unas espuelas en señal de que había sido caballero ${ }^{35}$ : «que me vistan un hábito et panos do mais probre frade profeso... et que me ponan vistido en ese panos eno leito en que levan os frades professos dese moesterio quando os han soterrar et ponan y conmigo hua espada miña guarnida de ferro et huas esporas en sinal que foi cavaleyro ${ }^{36}$. El testimonio es sumamente interesante ya que constata cómo, al mismo tiempo que reclama elementos que podrían considerarse suntuarios -espada, espuelas-, está reclamando una mortaja humilde y una sepultura en un monasterio, lo que refuerza aún más la idea del valor simbólico de reivindicación de su posición en el orden social que desempeñan los atributos caballerescos. Es un soldado al servicio del rey, pero además es un caballero investido por la nobleza de su sangre y de ello dan fe las armas que le está permitido exhibir en el momento de su funeral.

En un contexto histórico más preciso, la presencia en contextos funerarios de «espuelas doradas» tiene que ver, sin duda, con la configuración de la caballería noble y con el peso que la investidura y los símbolos adquieren en este momento. La mayor parte de las evidencias conocidas hasta la fecha se ubican en lo que se ha denominado el periodo de "definición» de las ideas sobre la caballería en Castilla, enmarcado entre 1250 y $1350^{37}$, en el

Universidad de Santiago de Compostela, 1992, pp. 27-36. Su sepultura en Sobrado estaría atestiguada por una referencia en la Historia manuscrita del monasterio de Sobrado del siglo XviI. Existe otra versión, transmitida por el historiador compostelano A. López Ferreiro, según la cual el caballero recibió sepultura en la catedral de Santiago de Compostela, conforme a su segundo testamento, y allí se hallaron las «espuelas de oro» en el siglo XIX, pero no la espada.

34 Gutiérrez Cuenca, Génesis y evolución del cementerio medieval en Cantabria, p. 614. De hecho, algunos autores consideran la sepultura del infante Fernando de la Cerda como el modelo de la sepultura caballeresca castellana. Porro Girardi, La investidura de armas en Castilla, p. 192.

35 SÁnchez Ameijeiras, María Rocío. «El arnés y el armamento del caballero medieval gallego (13501450)». Acta Historica et Archaeologica Mediaevalia, 1989, vol. 10, pp. 427-436.

36 López Ferreiro, Antonio. Historia de la Santa A. M. Iglesia de Santiago de Compostela, Tomo VI. Santiago de Compostela: Seminario Conciliar Central, 1903, p. 117.

37 Rodríguez Velasco, Jesús. «Para una periodización de las ideas sobre la caballería en Castilla (ca. 1250-1500)». En Lucía MejíAs, José Manuel (ed.). Actas del VI Congreso Internacional de la 
REIVINDICACIÓN DE ESTATUS Y COSTUMBRES FORÁNEAS EN EL REGISTRO FUNERARIO MEDIEVAL CASTELLANO. A PROPÓSITO DE DOS CASOS DE CANTABRIA ENRIQUE GUTIÉRREZ CUENCA

que se dará forma a la investidura de armas, un elemento clave para diferenciar la caballería noble de la llamada «caballería popular». Esta ceremonia, codificada por primera vez para el ámbito castellano en el Título XXI de la II Partida de Alfonso X el Sabio (c 1251-1265) ${ }^{38}$, define los atributos propios del caballero, al que durante la investidura se le han de «calçar las espuelas» y "cennir el espada» (L. XIV).

Este interés por la codificación del estamento está reflejando la maniobra alfonsí de emplear la caballería como recurso político de la monarquía frente a la nobleza descontenta y levantisca, dando forma a una institución que define al mismo tiempo un lazo solidario entre la nobleza y la corona, y un marco privilegiado de relación entre ambos cuerpos, creando una caballería de linaje subordinada a los intereses reales ${ }^{39}$.

Es una tendencia que continuará, incluso incrementándose, durante el reinado de Alfonso $\mathrm{XI}^{40}$ y marcará el carácter particular de la caballería bajomedieval castellana frente a otras del ámbito continental.

El uso, por parte del noble, de los atributos distintivos de su condición de caballero investido toma en este contexto un significado social, en tanto que lo distingue del simple caballero villano potenciando el concepto de linaje, pero también político. Define la posición del noble en el sistema, no solo reivindicando el carácter exclusivo de la nobleza de sangre que representa la investidura de armas, sino también haciendo explícito su vínculo con el rey, garante último de la posición privilegiada de los integrantes de la orden de caballería. Es una orden reservada a los nobles ${ }^{41}$ y son ellos los que en sus funerales, exhibiendo los símbolos de la investidura, en este caso las «espuelas doradas», hacen una última reivindicación de un estatus que se transmite a sus herederos, continuadores del linaje.

\section{Las vasijas incensario de Santa María de Castro Urdiales}

Las obras de restauración de la girola de la iglesia gótica de Santa María de la Asunción (Castro Urdiales, Cantabria) han permitido documentar una porción del cementerio medieval situado en el cerro de Santa María. El seguimiento y control arqueológico llevado a cabo por J. Marcos Martínez ${ }^{42}$ en 2012 ha permitido identificar la presencia de

Asociación Hispánica de Literatura Medieval. Alcalá de Henares: Universidad de Alcalá, 1997, vol. 2, pp. 1335-1346.

${ }_{38}$ Que no estuviese codificada no significa que no se practicase la investidura, sobre todo en la esfera regia. Palacios Martín, Bonifacio. «Investidura de armas de los reyes espańoles en los siglos XII y XiII». En Actas del I Simposio Nacional Las Armas en la Historia (siglos X-XIV). Madrid: Consejo Superior de Investigaciones Científicas, 1988, pp. 153-192.

39 Vallejo Naranjo, Carmen. La caballería en el arte de la Baja Edad Media. Sevilla: Universidad de Sevilla, 2013, pp. 176-179. En la misma línea se expresan otros autores: MARTin, Georges. «Control regio de la violencia nobiliaria. La caballería según Alfonso X de Castilla (comentario al título XXI de la Segunda Partida)». Annexes des Cahiers de Linguistique et de Civilisation Hispaniques Médiévales, 2004, vol. 16, pp. 219-234.

40 García Díaz, Isabel. "La política caballeresca de Alfonso XI». Miscelánea Medieval Murciana, 1984, vol. 11, pp. 117-134.

41 Porro Girardi, La investidura de armas en Castilla, p. 91.

42 Marcos Martínez, Javier. Informe de los sondeos y seguimiento arqueológico de la obra de conservación de los paramentos exteriores de la girola de la iglesia de Santa Maria de la Asunción de Castro Urdiales. 
REIVINDICACIÓN DE ESTATUS Y COSTUMBRES FORÁNEAS EN EL REGISTRO FUNERARIO MEDIEVAL CASTELLANO. A PROPÓSITO DE DOS CASOS DE CANTABRIA ENRIQUE GUTIÉRREZ CUENCA

tumbas excavadas en la roca y de lajas, una parte de ellas afectadas por la construcción gótica, además de diversas estelas discoideas procedentes del cementerio medieval reaprovechadas como material de construcción en dicha fábrica y en los adosados posteriores al edificio.

En total se han documentado 23 tumbas, la mayor parte de las cuales son tumbas excavadas en la roca caliza. Únicamente se ha podido determinar con precisión la forma de siete tumbas antropomorfas, con la cabecera de tendencia cuadrangular, y dos rectangulares. Todas estaban orientadas hacia el E, con ligeras variaciones. En la mayor parte de los casos se había practicado un rebaje perimetral para el encaje de la cubierta, aunque solo en una tumba estaba en su posición original.

Todas las tumbas identificadas corresponden, por sus dimensiones, a individuos adultos o juveniles; no hay ninguna infantil. No se conservaban los restos óseos en su posición original, salvo en un caso, seguramente debido a las alteraciones producidas por la construcción del templo y por remociones de tierra posteriores, ya que algunas zonas del entorno de la iglesia fueron utilizadas como lugar de sepultura en los siglos XVIII y XIX.

El hallazgo de dos hebillas de aleación de cobre con tipología propia de los siglos XIV-XV se ha relacionado con la recuperación de la «inhumación vestida» en época bajomedieval, pero ambos ejemplares aparecieron fuera de contexto y no es segura la relación con las sepulturas.

La superposición del edificio gótico sobre las estructuras funerarias y la presencia en una de las tumbas de cerámica fechada en torno al siglo XII, constituyen las principales referencias para proporcionar una cronología ante quam a las tumbas excavadas en la roca. J. Marcos Martínez desestima la relación de esta necrópolis con la iglesia de San Pedro, situada inmediatamente al $S$ de la iglesia de Santa María y documentada desde finales del siglo XII. Baraja la posibilidad de que exista un templo anterior al gótico bajo la fábrica actual del templo mayor de Castro Urdiales, aunque este extremo está pendiente de comprobación. Es difícil datar con precisión las estructuras documentadas, pero es razonable suponer que, como otros lugares con tumbas excavadas en la roca, su origen debe ser altomedieval. Hay que destacar que, junto con la tumba documentada por J. Carballo en Vegas de $\mathrm{Astrago}^{43}$, es el único caso conocido hasta el momento en la vertiente costera de Cantabria con tumbas excavadas en la roca.

La estructura funeraria mejor conservada era la tumba IX, excepcional en muchos aspectos. Se trata de una tumba excavada en la roca cuya cabecera estaba bajo los cimientos del edificio gótico. La cubierta, compuesta por losas de granito de origen foráneo, ocupaba su posición original y en el interior se conservaban restos óseos de dos individuos adultos, aparentemente incompletos y parcialmente desarticulados, con algunas conexiones anatómicas que han sido interpretadas como una colocación en decúbito prono de uno de los sujetos, o, a nuestro entender, la manipulación y desplazamiento

Santander: 2013. Informe elaborado para el Servicio de Patrimonio Cultural de Cantabria, inédito. Agradecemos a J. Marcos Martínez la cesión del informe de excavación inédito y del material gráfico referido a la actuación arqueológica que se incorpora en el presente artículo. Marcos MarTínez, Javier. «Trabajos de arqueología en la restauración de la girola de Santa María de Castro Urdiales». Clavis, 2013, vol. 6, pp. 1-25.

43 Gutiérrez Cuenca, Génesis y evolución del cementerio medieval en Cantabria, pp. 200-201. 
REIVINDICACIÓN DE ESTATUS Y COSTUMBRES FORÁNEAS EN EL REGISTRO FUNERARIO MEDIEVAl CASTELLANO. A PROPÓSITO DE DOS CASOS DE CANTABRIA

de algunos huesos cuando el cuerpo aún no estaba completamente esqueletizado. Junto a los restos óseos se han depositado tres vasijas incensario con la panza perforada que contenían carbones y macrorrestos vegetales en su interior ${ }^{44}$, una a los pies de la tumba, ubicada posiblemente en su posición original, y las otras dos en el tercio superior, una de ellas desplazada de lugar (Fig. 5).

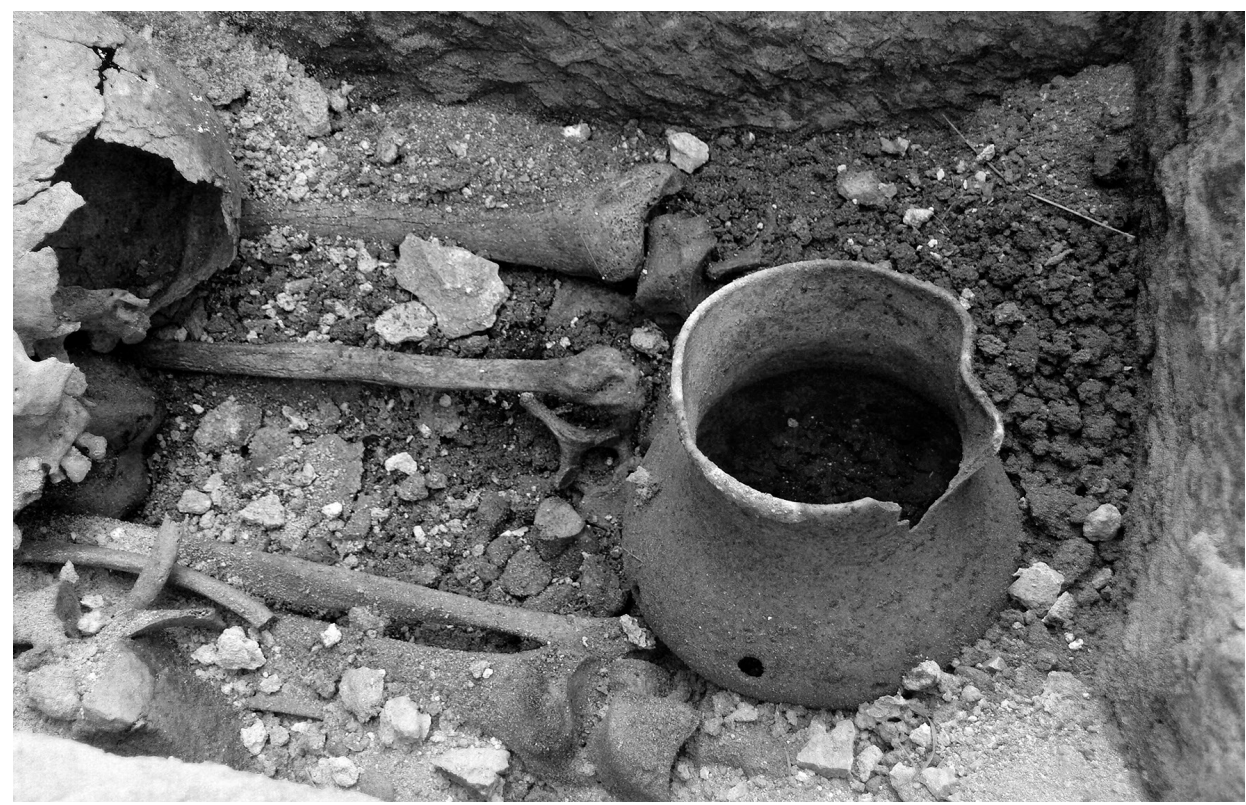

FIG. 5. Vasija incensario con carbones en su interior, colocada a los pies de la tumba IX de Santa María de la Ascensión de Castro Urdiales. Foto: J. Marcos Martínez.

La primera de estas vasijas incensario es una jarra de cuerpo globular, fondo plano, con pico vertedor y asa de cinta moldurada de $149 \mathrm{~mm}$ de altura y $102 \mathrm{~mm}$ de diámetro de boca. Está fabricada a torno y muestra cocción oxidante regular, a juzgar por el color ocre-rosáceo de las paredes. En la panza se han realizado cinco perforaciones circulares post-cocción. Tiene decoración en el cuello mediante líneas incisas finas y en el asa, con impresiones tipo "punta de navaja». En el interior se conservaban restos de carbones y otros macrorrestos vegetales. Estaba colocada en el tercio superior de la tumba IX.

La otra vasija incensario colocada en el tercio superior de la tumba IX es una jarra de cuerpo globular, fondo convexo, cuello vertical muy marcado, con pico vertedor separado

44 Sopelana, Itxaso. Análisis de macrorrestos vegetales de Santa María de la Asunción. Vitoria: Universidad del País Vasco, 2013. Informe inédito. El estudio de los restos carpológicos determina la presencia de trigo, cebada y lenteja además de Salvia sp. Esta última planta puede ser utilizada como planta aromática y medicinal. No se ha realizado identificación de los restos de carbón. El informe nos ha sido facilitado por J. Marcos Martínez, director de la actuación arqueológica. 
REIVINDICACIÓN DE ESTATUS Y COSTUMBRES FORÁNEAS EN EL REGISTRO FUNERARIO MEDIEVAL CASTELLANO. A PROPÓSITO DE DOS CASOS DE CANTABRIA ENRIQUE GUTIÉRREZ CUENCA

y asa de cinta moldurada. Tiene unas dimensiones de $120 \mathrm{~mm}$ de altura y $69 \mathrm{~mm}$ de diámetro de boca. Está fabricada a torno y muestra cocción oxidante regular, a juzgar por el color ocre-rosáceo de las paredes. En la panza se han realizado siete perforaciones circulares post-cocción. Presenta decoración pintada de color rojo oscuro en el cuello y el cuerpo, compuesta por líneas que forman motivos reticulados, y líneas horizontales en el asa. En el interior se conservaban restos de carbones y otros macrorrestos vegetales.

El tercer ejemplar de vasija incensario de cerámica es una jarra de cuerpo globular, fondo convexo, con pico vertedor lateral y asa de cinta moldurada, muy similar a la primera de las descritas. Tiene una altura de $128 \mathrm{~mm}$ y un diámetro de boca de 105 $\mathrm{mm}$. Está fabricada a torno y muestra cocción oxidante regular, a juzgar por el color ocre-rosáceo de las paredes. En la panza se han realizado seis perforaciones circulares post-cocción. Está decorada en la zona del cuello mediante líneas incisas. En el interior se conservaban restos de carbones y otros macrorrestos vegetales. Estaba colocada a los pies de la tumba IX.

Las características de las vasijas (Fig. 6), jarras de uso común acondicionadas para ser utilizadas como incensario, algo habitual en la mayor parte de los casos conocidos en contexto funerario ${ }^{45}$, son similares a modelos fechados en el País Vasco entre el siglo IX y la primera mitad del siglo $\mathrm{xII}^{46}$, al menos los ejemplares no pintados. El depósito de vasijas incensario en las sepulturas es una costumbre completamente desconocida, hasta el momento, en el registro funerario de la Península Ibérica. Sin embargo, es una práctica

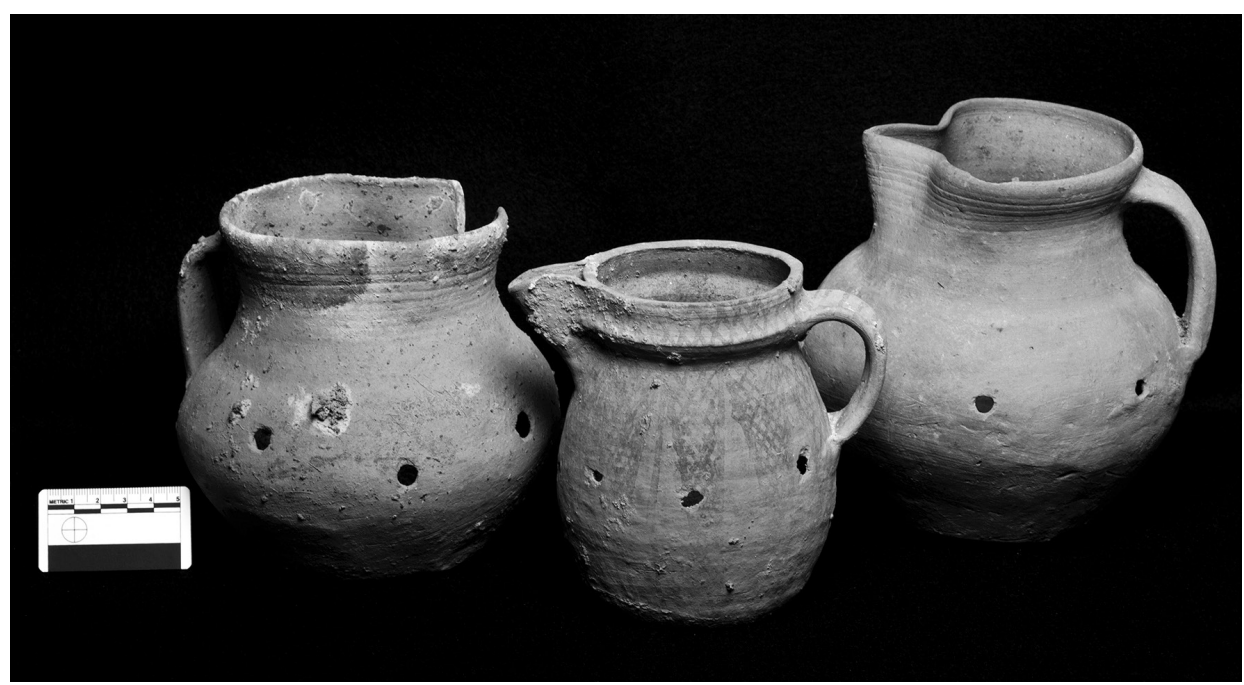

FIG. 6. Vasijas incensario de Santa María de la Ascensión de Castro Urdiales. Foto: J. Marcos Martínez.

45 Schwertz, Daniel. «Dépôts funéraires médiévaux en Vendômois et dans le Centre». Revue Archéologique du Centre de la France, 1981, vol. 20, n. ${ }^{\circ} 2$, pp. 27-40.

46 Solaun Bustinza, José Luis. La cerámica medieval en el País Vasco (siglos VIII-XIII). Vitoria: Universidad del País Vasco-Gobierno Vasco, 2005, pp. 226-227. 
REIVINDICACIÓN DE ESTATUS Y COSTUMBRES FORÁNEAS EN EL REGISTRO FUNERARIO MEDIEVAl CASTELLANO. A PROPÓSITO DE DOS CASOS DE CANTABRIA

muy bien documentada en algunas regiones septentrionales y centrales de Francia entre los siglos XII y $\mathrm{XV}^{47}$.

En opinión de J. Marcos Martínez la presencia de estos objetos en Castro Urdiales podría estar en relación con los maestros de obra de la fábrica gótica, venidos de Francia en el siglo XIII, lo que podría tener bastante sentido. De hecho, todos los investigadores que han estudiado la construcción del edificio coinciden en la posibilidad de que la obra fuese iniciada por un maestro francés ${ }^{48}$. No obstante, lo interpreta como un gesto no relacionado con los funerales, sino con un momento posterior, una especie de muestra de respeto por las tumbas sobre las que se instala la iglesia, un «rito con fines penitenciales y de asistencia al difunto", e incluso supone que pudo realizarse en todas las tumbas afectadas por la nueva construcción ${ }^{49}$. Sin embargo, todas las referencias, tanto iconográficas como arqueológicas, parecen señalar un vínculo estrecho del tipo de vasijas con el oficio funerario y no parece probable que se hayan usado en otro tipo de prácticas ${ }^{50}$. Por nuestra parte, nos inclinamos a pensar que, como era habitual y veremos con más detalle más adelante, fueron utilizadas durante el oficio funerario y después depositadas acompañando a la sepultura, conforme a la costumbre conocida en el norte de Francia.

47 Husi, Philippe; Lorans, Elisabeth y Theureau, Christian. «Les pratiques funéraires à SaintMexme de Chinon du ve au XviII siècle». Revue Archéologique du Centre de la France. 1990, vol. 29, n. ${ }^{\mathrm{e}}$ 2, pp. 131-168. Prigent, Daniel. «Les céramiques funéraires (XI ${ }^{\mathrm{e}}$-XVII ${ }^{\mathrm{e}}$ siècle)». En Galinié, Henri y Zadora-Rio, Elisabeth (eds.). Archéologie du cimetière chrétien. Tours: Revue Archéologique du Centre de la France, 1996, pp. 215-224.

48 Aunque existe cierto consenso en hacer coincidir el inicio de las obras de Santa María de la Asunción con las visitas giradas a la villa de Castro Urdiales por Alfonso VIII en 1208 y 1209, hay dos propuestas para el origen de las trazas empleadas en la obra y, por extensión, de la posible procedencia de los constructores franceses. Por un lado, se ha propuesto un origen normando que entronca con la iglesia de Saint-Pierre de Lisieux y con la catedral de Coutances. Campuzano Ruiz, Enrique. El gótico en Cantabria. Santander: Estudio, 1985, p. 104. Alonso Ortiz, Luis Alberto y Campuzano Ruiz, Enrique. "CComo barco sorprendido por el temporal...”. Iglesia de Santa María de Castro Urdiales». Clavis, 2013, vol. 6, pp. 30-38. Este origen franco-normando es el que defiende también J. Marcos Martínez. Otros investigadores han considerado un origen borgoñón, relacionando las trazas de Santa María de la Asunción con la iglesia de Saint-Pierre de Bourges y con la propia catedral de Bourges. Aramburu ZabalaHiguera, Miguel Ángel. «Diseño y realización en el arte gótico de las villas de la costa de Cantabria». En 1296-1996. VII Centenario de la Hermandad de las Marismas. Castro Urdiales: Ayuntamiento de Castro Urdiales, 1996, pp. 75-88. En ambos casos se plantea la posibilidad, además, de que las influencias francesas lleguen a través de maestros castellanos, lo que complicaría la conexión entre las vasijas incensario y los constructores de la iglesia.

49 Marcos Martínez, «Trabajos de arqueología en la restauración de la girola de Santa María de Castro Urdiales», p. 6.

50 Que conozcamos, solo se ha propuesto un carácter votivo para un depósito de nueve vasijas incensario hallado en la nave de la iglesia de Saint-Géry de Rebecq (Bélgica), sin ningún tipo de relación con estructuras funerarias, que se supone fueron utilizadas en la consagración de la fábrica de los siglos XII-XIII. Bosquet, Dominique; Van Hove, Marie Laure; Van Nieuwenhove, Benjamin; Cerezo-Roman, Jessica; Challe, Sophie; Fievez, Sandrine; Lozet, Stéphanie; Vandenbranden, Chloé; Heller, Frédéric y WiLlems, Didier. «Rebecq: fouilles sur la Grand-Place à l'emplacement de l'église Saint-Géry». Chronique de l'Archéologie Wallonne, 2014, vol. 21, pp. 15-19. 
REIVINDICACIÓN DE ESTATUS Y COSTUMBRES FORÁNEAS EN EL REGISTRO FUNERARIO MEDIEVAL CASTELLANO. A PROPÓSITO DE DOS CASOS DE CANTABRIA ENRIQUE GUTIÉRREZ CUENCA

\section{UN GESTO FUNERARIO FORÁNEO EN UN PUERTO CASTELLANO}

El depósito de vasijas incensario en las sepulturas es una costumbre completamente inédita en el registro funerario pleno y bajomedieval de la Península Ibérica ${ }^{51}$. Como hemos señalado más arriba, el gesto documentado en la villa de Castro Urdiales debe interpretarse necesariamente como una trasposición de una práctica foránea, ajena al ceremonial propio de los funerales castellanos y propia del norte de Francia.

Es en ese espacio geográfico donde encontramos el mayor número de casos conocidos de vasijas incensario en contextos funerarios, una treintena de sitios que se concentran en el valle del Loira, la cuenca de París y Normandía (Mapa 2) y que ofrecen cronologías entre los siglos XII y XVI. En el valle del Loira se han estudiado diversos ejemplos del Vendôme, Tours y Orléans ${ }^{52}$, además de los identificados en las excavaciones en Rigny-Ussée ${ }^{53}$ y en Saint-Mexme de Chinon ${ }^{54}$. En la cuenca de París destacan lugares como Saint-Nicolas d'Acy ${ }^{55}$, Champlieu ${ }^{56}$ y Saint-Sauver de Melun ${ }^{57}$. En Normandía la costumbre está menos representada, aunque en los últimos ańos se han realizado interesantes descubrimientos en Saint-Pierre-sur-Dives ${ }^{58}$ y Thaon ${ }^{59}$. Fuera de estas regiones los

51 La presencia de cualquier tipo de vasija de cerámica acompañando a los difuntos es poco o nada habitual en el ámbito peninsular en momentos posteriores al siglo viII. Solo en algunas necrópolis del Vallès (Cataluña) aparecen vasijas en tumbas en torno a los siglos XI-XII. Roig Buxó, Jordi; Coll Riera, Joan Manel y Molina Vallmitjana, Josep Anton. «El vilatge medieval i l'església de Sant Esteve de Castellar Vell (Castellar del Vallès, Vallès Occidental)». Tribuna d'Arqueologia, 2002, vol. 1998-1999, pp. 305-322. RoIG Buxó, Jordi; Coll, Joan Manuel y Molina Vallmitjana, Josep Anton. «L'església de Sant Julià d'Altura (Sabadell, Vallès Occidental): resultats de les darreres intervencions arqueològiques (1998-1999)». Tribuna d'Arqueologia, 2003, vol. 1999-2000, pp. 255-272.

52 Schweitz, «Dépôts funéraires médiévaux en Vendômois et dans le Centre». Galinié, Henri. «Fouilles archéologiques sur le site de Saint-Pierre-le-Puellier, 1969-1974. Raport préliminaire». Bulletin de la Société Archéologique de Touraine, 1976, vol. XXXVIII, pp. 155-172. Baratin, Jean François. "Chronique d'archéologie médiévale. Les vases funéraires médiévaux du Musée de Pithiviers». Revue Archéologique du Centre de la France, 1973, vol. 12, n. ${ }^{\circ} 1-2$, pp 127-144.

53 Zadora-Rio, Elisabeth; Galinié, Henri; Baron, Marie-Claude; Husi, Philippe; Jouquand, Anne Marie; Martineau, Marie Christèle; Mascla, Jean Marcel; Poirot, Agata; Rodier, Xavier y Theureau, Christian. «Fouilles et prospections à Rigny-Ussé (Indre-et-Loire), rapport préliminaire 1986-1991». Revue Archéologique du Centre de la France, 1992, vol. 31, pp. 75-166.

54 Husi et ál., «Les pratiques funéraires à Saint-Mexme de Chinon du v au XVIII ${ }^{\mathrm{e}}$ siècle».

55 Bourry, Michel; La Phung Xuan, Franck; Da Silva, Mya Pereira; Cussenot, Olivier y Racinet, Philippe. "Vie" et mort dans le prieuré clunisien de Saint-Nicolas d'Acy: archéologie funéraire et anthropologie». Revue Archéologique de Picardie, 1991, vol. 1991, n.o 1-2, pp. 103-144.

56 Durand, Marc. Archéologie du cimetière médiéval au sud-est de l'Oise du VII au XVI siècle: relations avec l'habitat, évolution des rites et des pratiques funéraires, paléodémographie. Amiens: Revue Archéologique de Picardie, 1988, pp. 177-182.

57 Ravoire, Fabienne. «Melun (Seine-et-Marne), ancien prieuré Saint-Sauveur ( $\mathrm{x}^{\mathrm{e}}$-XviII ${ }^{\mathrm{e}}$ siècles). Aperçu sur la céramique du prieuré». Bulletin du Centre d'Études Médiévales d'Auxerre, 2006, vol. 10 [doi: $10.4000 /$ cem.445].

58 Alduc-Le Bagousse, Armelle; Blondiaux, Joël; Desloges, Jean y Maneuvrier, Christophe. "Les sépultures d'un sanctuaire bénédictin normand: le chœur de l'abbatiale de Saint-Pierre-sur-Dives». En Alduc-Le Bagousse, Armelle (ed.). Inhumations et édifices religieux au Moyen Âge entre Loire et Seine. Caen: Centre de Recherches Archéologiques et Historiques Médiévales, 2004, pp. 181-206.

59 Delahaye, François. "Les pots à encens découverts à Thaon». Bulletin de l'Association des Amis de la Vieille Église de Thaon, 2008, vol. 8, p. 5. 


\section{REIVINDICACIÓN DE ESTATUS Y COSTUMBRES FORÁNEAS EN EL REGISTRO FUNERARIO MEDIEVAl CASTELLANO. A PROPÓSITO DE DOS CASOS DE CANTABRIA ENRIQUE GUTIÉRREZ CUENCA}

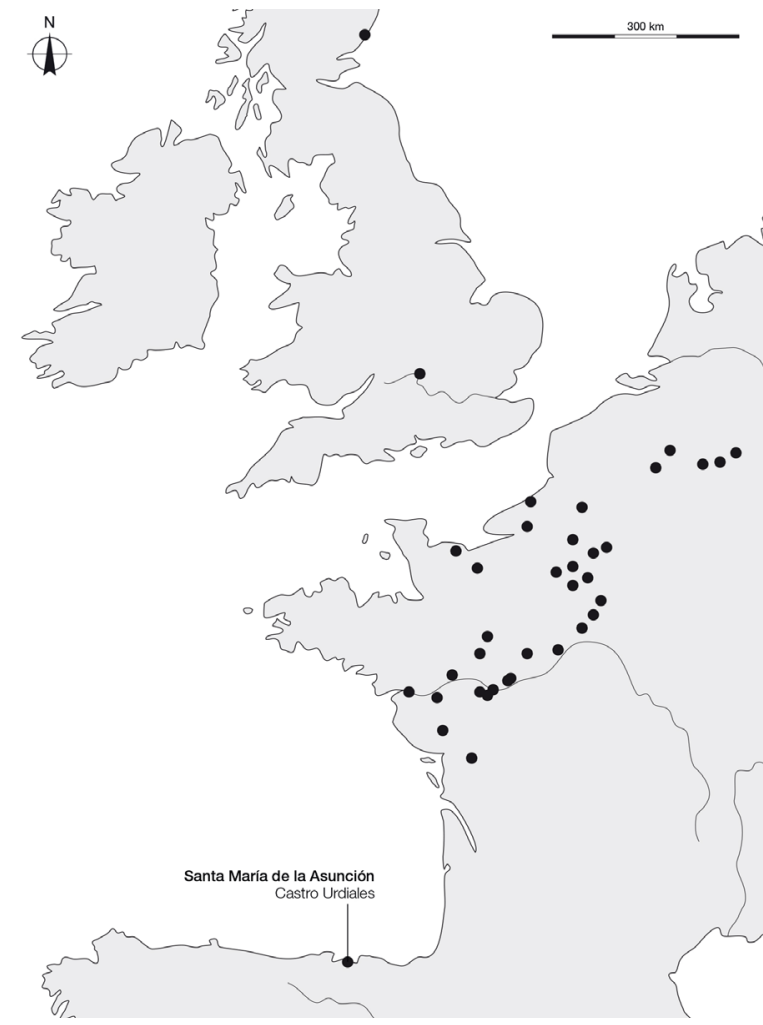

Mapa 2. Distribución de lugares en los que se han hallado vasijas incensario de panza perforada en Europa Occidental. Mapa: autor. hallazgos son poco frecuentes, siendo Saint-Pierre de Melle ${ }^{60}$, ya en Aquitania, el punto más meridional de la distribución conocida.

Otra zona en la que se ha documentado el uso de vasijas incensario es la Región Valona, en Bélgica, donde se conocen al menos cinco localizaciones en el valle del Mosa, Rebecq y Quarengnon ${ }^{61}$.

Sin conexión aparente con el núcleo continental, se conocen dos casos aislados en las Islas Británicas, uno en Montrose (Escocia) y otro en Oxford (Inglaterra) ${ }^{62}$. Mención aparte merece la frecuente presencia en un número importante de tumbas danesas, fechadas del siglo XIII en adelante, de recipientes de cerámica con carbones en su interior -aunque sin perforaciones en la panza- que P. K. Madsen ha puesto en relación con las vasijas incensario francesas contemporáneas ${ }^{63}$.

El hallazgo recurrente de

este tipo de recipientes en sepulturas, como sucede en el caso de Castro Urdiales, pone de manifiesto el carácter específicamente funerario de su uso, tal y como hemos avanzado más arriba. También parece clara su función de quemadores de incienso, sugerido por la presencia de restos de carbón en su interior y por las perforaciones en la panza para facilitar la combustión y ratificado por recientes análisis que han conseguido detectar la

60 Prigent, «Les céramiques funéraires $\left(\mathrm{XI}^{\mathrm{e}}-\mathrm{XVII}^{\mathrm{e}}\right.$ siècle)».

61 Challe, Sophie; De Groote, Koen y Leblois, Eric. "Les céramiques funéraires en Belgique entre le XII et le début du Xve siècle». Archaeologia Mediaevalis, 2013, vol. 36, pp. 32-34. Baeten, Jan; Deforce, Koen; Challe, Sophie; De Vos, Dirk y Degryse, Patrick. «Holy Smoke in Medieval Funerary Rites: Chemical Fingerprints of Frankincense in Southern Belgian Incense Burners». Plos One, 2014, vol. 9, n. 11 [doi: 10.1371/journal.pone.0113142].

${ }^{62}$ Gilchrist, Roberta y Slonne, Barney. Requiem. The medieval monastic cemetery in Britain. London: Museum of London Archaeology Service, 2005, p. 165.

63 Madsen, Per Kristian. «A French Connection. Danish Funerary Pots-a Group of Medieval Pottery». Journal of Danish Archaeology, 1983, vol. 2, n. ${ }^{\circ}$ 1, pp. 171-183. 
REIVINDICACIÓN DE ESTATUS Y COSTUMBRES FORÁNEAS EN EL REGISTRO FUNERARIO MEDIEVAL CASTELlaNO. A PROPÓSITO DE DOS CASOS DE CANTABRIA ENRIQUE GUTIÉRREZ CUENCA

huella química de esta resina aromática en los propios vasos ${ }^{64}$. A la correcta interpretación de los restos materiales contribuyen también los datos aportados por las fuentes escritas e iconográficas, sobre todo porque completan la información sobre el uso de las vasijas en los momentos previos a su depósito en la sepultura.

Las descripciones más detalladas las encontramos en dos testamentos franceses del siglo Xv. El testamento de Colin d'Autheuil (1412), un burgués de la villa de Châteaudun, menciona el uso de los vasos incensario durante el cortejo fúnebre junto con otras costumbres de los funerales de las personas de cierta posición económica como las donaciones a los pobres, la dotación de cera para luminarias o la lectura del salterio en la vigiliaa $^{65}$ : «aux pauvres qui porteront le poz à l'encens autour de son corps, le jour de son obit, à chacun dix deniers tournois». Mayor detalle aún ofrece el testamento de Guillaume Berri (1494), un clérigo de Nantes, en el que se precisa la presencia de cuatro niños «avec un cierge allumé d'une main, et de l'autre un pot de terre neuf, dans lequel il y aura brasier de charbon et encens sur icelui, et moi ensépulturé; lesdits pots seront jettés en ma fosse, ainsi qu'il est en bonne coutume de faire» ${ }^{66}$.

Vemos, por tanto, cómo las vasijas incensario acompañan el traslado del difunto y cómo posteriormente se depositan en la tumba, tal y como evidencia el registro arqueológico. Entre ambos gestos, los testimonios iconográficos nos ilustran acerca del papel que desempeñan durante la celebración del oficio fúnebre dentro de la iglesia. No pasa de media docena el número de imágenes conservadas en libros de horas de los siglos XIV y $\mathrm{XV}^{67}$, con representaciones que muestran varios vasos colocados alrededor del ataúd con las brasas encendidas y el humo del incienso saliendo por la boca del recipiente (Fig. 7).

Desde los primeros estudios referidos a la presencia de este tipo de vasijas en contexto funerario su uso se puso en relación con sepulturas privilegiadas ${ }^{68}$, sobre todo porque era este tipo de tumbas el que se "exploraba" y deparaba hallazgos en el siglo XIX. Esta interpretación sigue vigente en estudios más recientes que hacen notar la relación recurrente de vasijas incensario con sepulturas de adultos preferentemente de clase social elevada ${ }^{69}$, tanto del ámbito civil como del eclesiástico ${ }^{70}$. En el mismo sentido apuntan los testimonios referidos más arriba y otros como una imagen de las Belles Heures de Jean de France, duc de Berry en las que el quemador de incienso acompańa la vigilia de un monje nimbado ${ }^{71}$ o el relieve que representa los funerales del príncipe Luis de Francia $(\dagger 1260)^{72}$.

64 BaEten et ál., «Holy Smoke in Medieval Funerary Rites».

65 Robreau, Bernard. «L'église Saint-Lubin de Châteaudun (Eure-et-Loir)». Revue Archéologique du Centre de la France, 1984, vol. 23, n. ${ }^{\circ}$ 1, pp. 99-124.

${ }_{66}$ Prigent, «Les céramiques funéraires ( $\mathrm{XI}^{\mathrm{e}}$-XVII ${ }^{\mathrm{e}}$ siècle)», p. 217.

67 BNF Latin 18014, fols. 134v y 217r. BNF Ms. Lat. 924, fol. 177r. BNF NAL 3093, fol. 103v. BM Besançon Ms. 144, fol. 77. Pierpont Morgan Library Ms.157, fol. 129v.

68 Cochet, Jean Benoît. «Mémoire sur la coutume de placer des vases dans la sépulture de l'homme, et spécialement dans les sépultures chrétiennes depuis le $\mathrm{XI}^{\mathrm{e}}$ jusqu'au $\mathrm{XvIII}^{\mathrm{e}}$ siècle». Bulletin Monumental, 1856, vol. 22, pp. 329-363 y 425-446.

69 PRIGENT, «Les céramiques funéraires ( $\mathrm{XI}^{\mathrm{e}}$-XVII ${ }^{\mathrm{e}}$ siècle)».

70 Alexandre-Bidon, Danièle. La mort au Moyen Âge, XIIr-XVI siècle. Paris: Hachette, 1998, p. 144.

71 MOMA Acc 54.1.1, fol. 194v.

72 Musée Carnavalet, AP 865. 


\section{REIVINDICACIÓN DE ESTATUS Y COSTUMBRES FORÁNEAS EN EL REGISTRO FUNERARIO MEDIEVAL CASTELLANO. A PROPÓSITO DE DOS CASOS DE CANTABRIA \\ ENRIQUE GUTIÉRREZ CUENCA}
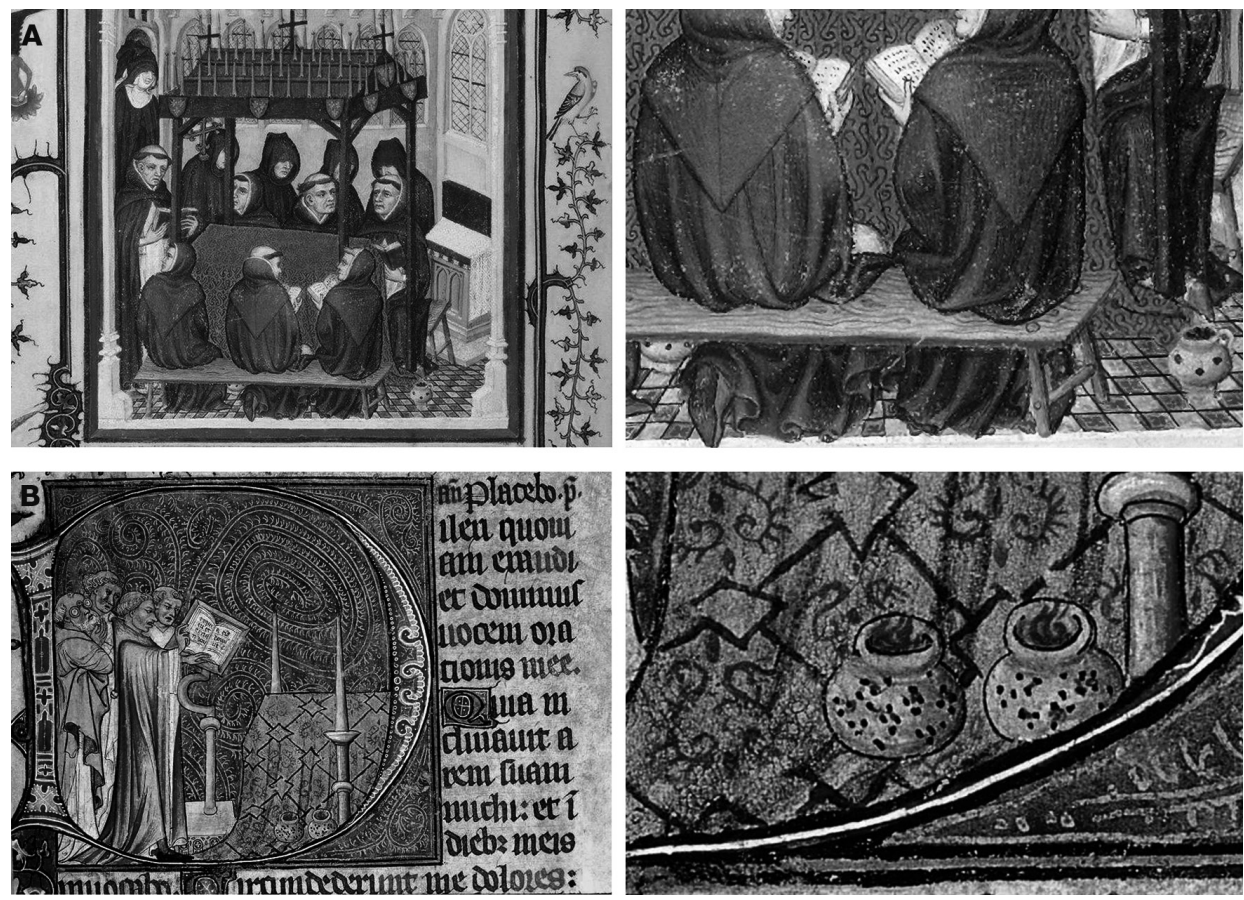

Fig. 7. Utilización de vasijas incensario durante el oficio fúnebre. A: BNF NAL 3093, f. 103v. B: BM Besançon Ms. 144, fol. 77.

Para explicar cómo una práctica concreta y definida, una «bonne coutume» con un área de distribución geográfica concreta, llega a otros lugares se han tratado de buscar siempre vínculos con el territorio de origen. Así, en el caso de Dinamarca, P. K. Madsen considera que la sepultura «a la francesa», acompañada de vasijas con carbones, se hace popular entre las clases altas danesas como parte de los influjos culturales procedentes de Francia, consecuencia de contactos oficiales y personales que se producen entre los dos países a partir del siglo XII. Particularmente, se fija en las jerarquías eclesiásticas que estudian en París y retornan a Dinamarca, donde reproducen influencias culturales tanto en el ámbito concreto de las prácticas funerarias como en otros campos, como la introducción de la arquitectura gótica ${ }^{73}$. En una línea similar se interpreta la presencia ocasional de vasijas incensario en las Islas Británicas, que respondería a contactos con las zonas en las que es una práctica consolidada. Se trataría de visitantes franceses o daneses -siguiendo a P. K. Madsenque fueron enterrados conforme a la costumbre de su lugar de origen, lo que implicaría que o bien dieron detalladas instrucciones sobre cómo deberían celebrarse sus funerales, o era conocido en las comunidades locales cómo proceder con esos visitantes ${ }^{74}$.

73 Madsen, «A French Connection. Danish Funerary Pots», p. 181.

74 Gilchrist y Sloane, Requiem. The medieval monastic cemetery in Britain, p. 165. 
REIVINDICACIÓN DE ESTATUS Y COSTUMBRES FORÁNEAS EN EL REGISTRO FUNERARIO MEDIEVAL CASTELLANO. A PROPÓSITO DE DOS CASOS DE CANTABRIA ENRIQUE GUTIÉRREZ CUENCA

En ambos casos se descarta la opción de una convergencia cultural o un desarrollo independiente de prácticas similares. Tampoco lo contemplamos para el caso castreño. Son demasiadas las coincidencias en la repetición de un gesto que se realiza de forma prácticamente idéntica en todos los lugares donde está presente, incluso en los detalles menores: se emplean vasijas de uso cotidiano, se perforan para convertirlas en incensarios, se utiliza más de un vaso, se deposita con más o menos cuidado en la tumba tras el empleo en los funerales, etc. Ello obliga a pensar que quienes realizan el proceso lo conocen bien. Para Castro Urdiales se ha propuesto a los constructores de la iglesia gótica a comienzos del siglo XIII, a los que se considera de origen normando ${ }^{75}$, aunque se podría plantear una opción más plausible atendiendo a los contactos comerciales de la villa costera con los puertos franceses.

Podría tener que ver con la presencia de una colonia estable de comerciantes franceses en Castro Urdiales que siga viviendo conforme a los usos y costumbres de su lugar de procedencia. En estas circunstancias, los funerales de un miembro señalado de la comunidad se celebrarían de la misma forma que se hubiese hecho en su lugar de origen, manifestando también en las prácticas funerarias una diferencia respecto de los usos locales. Lamentablemente, la documentación castreña de los siglos XII y XIII no aporta información sobre esta hipotética colonia que solo estaría atestiguada por este gesto. Sabemos que la presencia de mercaderes francos y gascones está atestiguada al menos desde la primera mitad del siglo XIII en las villas cantábricas ${ }^{76} \mathrm{y}$, del mismo modo que el puerto francés de La Rochelle acoge colonias de mercaderes vascos, cántabros, asturianos y gallegos, que frecuentarán también el puerto de Nantes en su tránsito hacia Flandes ${ }^{77}$, es razonable pensar que se diesen las mismas circunstancias en sentido contrario.

La presencia de un gesto funerario tan característico y de origen tan bien definido podría constituir una prueba de la presencia de una comunidad de comerciantes franceses, probablemente originarios del valle del Loira, establecida en Castro Urdiales entre los siglos XII-XIII, desde el mismo momento del despegue de la actividad comercial de su puerto. Un grupo capaz de poner en práctica una costumbre ajena a la tradición local y de entender su significado y la relevancia de su mensaje como manifestación de la posición social del finado. Del mismo modo, es probable que esta voluntad de reproducir en su último tránsito las mismas costumbres que son «buenas costumbres» en su lugar de origen contuviese un componente de manifestación «étnica», nacional, de diferenciación individual y afirmación colectiva, dando un valor simbólico al mantenimiento de las costumbres propias en territorio ajeno.

75 Marcos Martínez, «Trabajos de arqueología en la restauración de la girola de Santa María de Castro Urdiales», p. 6.

76 Solórzano Telechea, Jesús Ángel. «Villas y redes portuarias en la fachada Atlántica del Norte peninsular en la Edad Media». En Val Valdivieso, María Isabel y Martínez Sopena, Pascual (eds.). Castilla y el mundo feudal: homenaje al profesor Julio Valdeón. Vol. 1. Valladolid: Universidad de Valladolid, 2009, pp. 485-502.

77 Arízaga Bolumburu, Beatriz. «La actividad comercial de los puertos vascos y cántabros medievales en el Atlántico». Historia. Instituciones. Documentos, 2008, vol. 35, pp. 25-43. 
REIVINDICACIÓN DE ESTATUS Y COSTUMBRES FORÁNEAS EN EL REGISTRO FUNERARIO MEDIEVAl CASTELLANO. A PROPÓSITO DE DOS CASOS DE CANTABRIA ENRIQUE GUTIÉRREZ CUENCA

\section{Conclusiones}

Hemos analizado dos casos particulares en los que la presencia de objetos en el registro funerario permite realizar una lectura acerca de su significado concreto que nos pone en relación con coordenadas históricas significativas del momento en el que se desarrollan.

La presencia de «espuelas doradas» en las sepulturas de San Martín de Elines nos habla de la conciencia sobre el papel de representación social que desempeñaban determinados objetos y que nos permiten identificar tales evidencias como «sepulturas de caballero». Su presencia en este centro monástico tiene que ver, sin duda, con la vinculación mediante patronazgo de un linaje castellano destacado en el que confluyen líneas de los Villalobos y los Manrique de Lara. Estos personajes se significan en sus funerales y en sus sepulturas mediante un ejercicio de reivindicación de un estatus concreto, mostrándose como miembros de esa caballería investida en la que solo participa la nobleza de sangre a la que da forma la monarquía en su propio beneficio a partir del siglo xiII. Es un momento en el que la escenificación de la desigualdad y la ostentación de la posición social del individuo fallecido o de su familia se expresa a través de este tipo de manifestaciones tangibles, pero también se completará con la celebración de funerales con fastuosos cortejos que se convierten en auténticos espectáculos ${ }^{78}$. Otros no afectan al contenido de la tumba o al atuendo del difunto, sino a su forma o a su emplazamiento, o se manifiestan a través de otras vías como las figuraciones heráldicas que empiezan a aparecer en sarcófagos y capillas funerarias como representación de la "herencia inmaterial de los linajes» ${ }^{79}$.

Por lo que respecta a las vasijas incensario de Santa María de Castro Urdiales, el innegable carácter de práctica foránea, importada, completamente ajena a la tradición funeraria castellana, nos pone en contacto con una realidad más compleja: el comportamiento diferencial del «extranjero» y el uso de las particularidades culturales territoriales como medio de diferenciación y cohesión. Completando los enfoques desarrollados hasta el momento ${ }^{80}$, nos abre la puerta a conocer mejor cómo vivían las colonias de mercaderes instaladas en los puertos con los que comerciaban a través de algunos gestos que ponen de manifiesto las dinámicas de integración en la sociedad local. El mantenimiento de determinadas costumbres locales respondería a una actitud conservadora, diferenciadora, seguramente frecuente en las primeras etapas de instalación en nuevos territorios.

78 Sánchez Ameijeiras, Rocío. «Un espectáculo urbano en la Castilla medieval: las honras fúnebres del caballero». En NúŃEz Rodríguez, Manuel (ed.). El rostro y el discurso de la fiesta. Santiago de Compostela: Universidad de Santiago de Compostela, 1994, pp. 141-158.

79 Solórzano Telechea, Jesús Ángel. Santander en la Edad Media: patrimonio, parentesco y poder. Santander: Universidad de Cantabria-Ayuntamiento de Torrelavega, 2002, p. 450.

80 Gautier-Dalché, Jean. «Les colonies étrangères en Castille: I. Au nord du Tage». Anuario de Estudios Medievales, 1980, vol. 10, pp. 469-486. Solórzano TelecheA, Jesús Ángel. «Los extranjeros en las villas portuarias de la Costa Cantábrica en la Baja Edad Media». En Arízaga Bolumburu, Beatriz; Mariño Veiras, Dolores; Díez Herrera, Carmen; Solórzano Telechea, Jesús Ángel; Gujjarro GonzÁlez, Susana y AÑíbarro Rodríguez, Jesús (eds.). Mundos medievales: espacios, sociedades y poder. Homenaje al Profesor José Ángel García de Cortázar, Tomo II. Santander: Universidad de Cantabria, 2012, pp. 1933-1947. 
REIVINDICACIÓN DE ESTATUS Y COSTUMBRES FORÁNEAS EN EL REGISTRO FUNERARIO MEDIEVAL CASTELLANO. A PROPÓSITO DE DOS CASOS DE CANTABRIA ENRIQUE GUTIÉRREZ CUENCA

La profundidad que permite alcanzar el estudio de estos casos bajomedievales, en los que las fuentes escritas o la iconografía contribuyen a aclarar algunas dudas que el contexto arqueológico por sí solo no permite resolver, nos hace plantear la posibilidad de que algunas ideas pueden aplicarse al estudio de otros periodos en los que hay más dudas. Nos referimos específicamente a la Alta Edad Media, donde el debate sobre el papel de los objetos en las prácticas funerarias está especialmente vivo ${ }^{81}$, pero se desarrolla sin establecer un diálogo con la investigación sobre etapas más recientes del medievo ${ }^{82}$, un enfoque que podría resultar muy enriquecedor. Las líneas de interpretación son similares en una y otra época, con el acento puesto bien en la identidad social, bien en la identidad étnica. Esto no se debe entender, no obstante, como una invitación a la extrapolación. Épocas diferentes merecen análisis distintos -contextuales en el sentido amplio del término-, pero mirar en una y otra dirección puede contribuir a mejorar la comprensión de comportamientos que pueden responder, en ocasiones, a pautas comunes que se manifiestan en el uso de mensajes codificados para cuya transmisión efectiva no se encuentra mejor escenario que las manifestaciones funerarias.

\section{REFERENCIAS BIBLIOGRÁFICAS}

Alduc-Le Bagousse, Armelle; Blondiaux, Joël; Desloges, Jean y Maneuvrier, Christophe. «Les sépultures d'un sanctuaire bénédictin normand: le chour de l'abbatiale de Saint-Pierresur-Dives». En Alduc-Le Bagousse, Armelle (ed.). Inhumations et édifices religieux au Moyen Agge entre Loire et Seine. Caen: Centre de Recherches Archéologiques et Historiques Médiévales, 2004, pp. 181-206.

AleXandre-Bidon, Danièle. La mort au Moyen Âge, XII ${ }^{e}$-XVI siècle. Paris: Hachette, 1998.

Alonso Ortiz, Luis Alberto y Campuzano Ruiz, Enrique. «"Como barco sorprendido por el temporal...”. Iglesia de Santa María de Castro Urdiales». Clavis, 2013, vol. 6, pp. 30-38.

Aramburu Zabala-Higuera, Miguel Ángel. «Diseño y realización en el arte gótico de las villas de la costa de Cantabria». En 1296-1996. VII Centenario de la Hermandad de las Marismas. Castro Urdiales: Ayuntamiento de Castro Urdiales, 1996, pp. 75-88.

Arízaga Bolumburu, Beatriz. «La actividad comercial de los puertos vascos y cántabros medievales en el Atlántico». Historia. Instituciones. Documentos, 2008, vol. 35, pp. 25-43.

Baeten, Jan; Deforce, Koen; Challe, Sophie; De Vos, Dirk y Degryse, Patrick. «Holy Smoke in Medieval Funerary Rites: Chemical Fingerprints of Frankincense in Southern Belgian Incense Burners». Plos One, 2014, vol. 9, n. ${ }^{\circ} 11$ [doi: 10.1371/journal.pone.0113142].

Baratin, Jean François. «Chronique d'archéologie médiévale. Les vases funéraires médiévaux du Musée de Pithiviers». Revue Archéologique du Centre de la France, 1973, vol. 12, n.o 1-2, pp $127-144$.

Bosquet, Dominique; Van Hove, Marie Laure; Van Nifuwenhove, Benjamin; Cerezo-Roman, Jessica; Challe, Sophie; Fievez, Sandrine; Lozet, Stéphanie; Vandenbranden, Chloé;

81 Quirós Castillo, Juan Antonio. «Trends and thoughts on the archaeology of Germanic cemeteries». Arqueología y Territorio Medieval, 2011, vol. 18, pp. 9-14.

82 GILCHRIST, Roberta. «Medieval archaeology and theory: a disciplinary leap of faith». En GILCHRIST, Roberta y Reynolds, Andrew (eds.). Reflections: 50 Years of Medieval Archaeology, 1957-2007. Leeds: Maney, 2009, pp. 385-408. 
REIVINDICACIÓN DE ESTATUS Y COSTUMBRES FORÁNEAS EN EL REGISTRO FUNERARIO MEDIEVAL CASTELLANO. A PROPÓSITO DE DOS CASOS DE CANTABRIA ENRIQUE GUTIÉRREZ CUENCA

Heller, Frédéric y Willems, Didier. «Rebecq: fouilles sur la Grand-Place à l'emplacement de l'église Saint-Géry». Chronique de l'Archéologie Wallonne, 2014, vol. 21, pp. 15-19.

Bourry, Michel; La Phung Xuan, Franck; Da Silva, Mya Pereira; Cussenot, Olivier y RaciNET, Philippe. "Vie" et mort dans le prieuré clunisien de Saint-Nicolas d'Acy: archéologie funéraire et anthropologie». Revue Archéologique de Picardie, 1991, vol. 1991, n. ${ }^{\circ}$ 1-2, pp. 103-144.

Campuzano Ruiz, Enrique. El gótico en Cantabria. Santander: Estudio, 1985.

Challe, Sophie; De Groote, Koen y Leblois, Eric. «Les céramiques funéraires en Belgique entre le XII ${ }^{\mathrm{e}}$ et le début du Xve siècle». Archaeologia Mediaevalis, 2013, vol. 36, pp. 32-34.

Cochet, Jean Benoît. «Mémoire sur la coutume de placer des vases dans la sépulture de l'homme, et spécialement dans les sépultures chrétiennes depuis le XI ${ }^{\mathrm{e}}$ jusqu'au XVIII ${ }^{\mathrm{e}}$ siècle». Bulletin Monumental, 1856, vol. 22, pp. 329-363 y 425-446.

Cortés, Ricardo Erasun y FAUre, Francisco Líbano. «Um conjunto de esporas medievais provenientes do convento de S. Salvador de Vilar de Frades (Barcelos)». Portugalia, 2008-2009, vol. 29-30, pp. 179-192.

Delahaye, François. «Les pots à encens découverts à Thaon». Bulletin de l'Association des Amis de la Vieille Église de Thaon, 2008, vol. 8, p. 5.

Domínguez Bolaños, Alonso. «La documentación arqueológica de los edificios prerrománicos de San Martín de Elines». En Iglesias Gil, José Manuel (ed.). Cursos sobre el Patrimonio Histórico 7. Actas de los XIII Cursos Monográficos sobre el Patrimonio Histórico (Reinosa, julioagosto 2002). Santander: Universidad de Cantabria, 2003, pp. 319-330.

Domínguez Bolaños, Alonso. Excavación arqueológica en San Martín de Elines. Valderredible (Cantabria). Ávila: 2004. Informe elaborado para el Servicio de Patrimonio Cultural de Cantabria, inédito.

Durand, Marc. Archéologie du cimetière médiéval au sud-est de l'Oise du VII au XVI siècle: relations avec l'habitat, évolution des rites et des pratiques funéraires, paléodémographie. Amiens: Revue Archéologique de Picardie, 1988.

Espinosa de los Monteros, Pablo. Teatro de la santa iglesia metropolitana de Sevilla. Sevilla: por Matías Clauijo, 1635.

GaLINIÉ, Henri. "Fouilles archéologiques sur le site de Saint-Pierre-le-Puellier, 1969-1974. Raport préliminaire». Bulletin de la Société Archéologique de Touraine, 1976, vol. XXXVIII, pp. 155-172.

García Állvarez-Busto, Alejandro. «La topografía funeraria del monasterio de Corias en la época medieval a partir de la arqueología y las fuentes escritas». Territorio, Sociedad y Poder. Revista de Estudios Medievales, 2012, vol. 7, pp. 129-178.

García Áluarez-Busto, Alejandro y Fernández Calderón, Noelia. «El caballero de las espuelas doradas. Análisis arqueológico de un enterramiento nobiliario medieval del monasterio de Corias». Gladius, 2014, vol. 34, pp. 135-152.

García DíAz, Isabel. «La política caballeresca de Alfonso XI». Miscelánea Medieval Murciana, 1984, vol. 11, pp. 117-134.

Gautier-Dalché, Jean. «Les colonies étrangères en Castille: I. Au nord du Tage». Anuario de Estudios Medievales, 1980, vol. 10, pp. 469-486.

Gilchrist, Roberta. "Medieval archaeology and theory: a disciplinary leap of faith». En GiLChrist, Roberta y Reynolds, Andrew (eds.). Reflections: 50 Years of Medieval Archaeology, 1957-2007. Leeds: Maney, 2009, pp. 385-408.

Gilchrist, Roberta y Sloane, Barney. Requiem. The medieval monastic cemetery in Britain. London: Museum of London Archaeology Service, 2005.

Gómez Moreno, Manuel. El Panteón Real de las Huelgas de Burgos. Madrid: Consejo Superior de Investigaciones Científicas, 1946. 
REIVINDICACIÓN DE ESTATUS Y COSTUMBRES FORÁNEAS EN EL REGISTRO FUNERARIO MEDIEVAL CASTELLANO. A PROPÓSITO DE DOS CASOS DE CANTABRIA ENRIQUE GUTIÉRREZ CUENCA

Gutiérrez Cuenca, Enrique. Génesis y evolución del cementerio medieval en Cantabria. Santander: Universidad de Cantabria, 2015 [doi: hdl.handle.net/10803/311798].

Härke, Heinrich. "Grave goods in early medieval burials: messages and meanings». Mortality, 2014, vol 19, n. ${ }^{\circ}$ 1, pp. 41-60.

Husi, Philippe; Lorans, Elisabeth y Theureau, Christian. «Les pratiques funéraires à Saint-Mexme de Chinon du v au XviII siècle». Revue Archéologique du Centre de la France. 1990, vol. 29, n. ${ }^{\circ} 2$, pp. 131-168.

Jiménez Gadea, Javier. «Acicate». En Jiménez Gadea, Javier; Echevarría Arsuaga, Ana; Tapia Sánchez, Serafín y Villanueva Zubizarreta, Olatz (eds.). La memoria de Alá. Mudéjares y moriscos de Ávila. Valladolid: Castilla Ediciones, 2011, pp. 48-49.

López Ferreiro, Antonio. Historia de la Santa A. M. Iglesia de Santiago de Compostela, Tomo VI. Santiago de Compostela: Seminario Conciliar Central, 1903.

López Sebastián, Paloma. «Espuelas doradas de Armentia». Akobe, 2008, vol. 9, pp. 34-38.

Madsen, Per Kristian. "A French Connection. Danish Funerary Pots-a Group of Medieval Pottery». Journal of Danish Archaeology, 1983, vol. 2, n. ${ }^{\circ}$ 1, pp. 171-183.

Marcos Martínez, Javier. «Trabajos de arqueología en la restauración de la girola de Santa María de Castro Urdiales». Clavis, 2013, vol. 6, pp. 1-25.

Marcos Martínez, Javier. Informe de los sondeos y seguimiento arqueológico de la obra de conservación de los paramentos exteriores de la girola de la iglesia de Santa María de la Asunción de Castro Urdiales. Santander: 2013. Informe elaborado para el Servicio de Patrimonio Cultural de Cantabria, inédito.

Martin, Georges. «Control regio de la violencia nobiliaria. La caballería según Alfonso X de Castilla (comentario al título XXI de la Segunda Partida)». Annexes des Cahiers de Linguistique et de Civilisation Hispaniques Médiévales, 2004, vol. 16, pp. 219-234.

Martínez Aguado, Inmaculada. «Un retablo para el convento de San Francisco de Valladolid del pintor Manuel Mateo». Boletín del Seminario de Estudios de Arte y Arqueología, 1999, vol. 65, pp. 335-342.

Martínez Martínez, María y Lora Serrano, Gloria. «Las inversiones suntuarias de la nobleza a fines de la Edad Media». En Vilar, Juan Bautista; Peñafiel Ramón, Antonio e Irigoyen López, Antonio (eds.). Historia y sociabilidad: homenaje a la profesora Maria del Carmen Melendreras Gimeno. Murcia: Universidad de Murcia, 2007, pp. 197-222.

Mártir Rizo, Juan Pablo. Historia de la muy noble y leal ciudad de Cuenca. Madrid: por los herederos de la viuda de P.o de Madrigal, 1629.

Palacios Martín, Bonifacio. «Investidura de armas de los reyes españoles en los siglos XII y XIII». En Actas del I Simposio Nacional Las Armas en la Historia (siglos X-XIV). Madrid: Consejo Superior de Investigaciones Científicas, 1988, pp. 153-192.

Pereda Llarena, Francisco Javier. Documentación de la Catedral de Burgos (1254-1293). Burgos: Catedral de Burgos, 1984.

Porro Girardi, Nelly Raquel. La investidura de armas en Castilla: del rey Sabio a los Católicos. Valladolid: Junta de Castilla y León, 1998.

Portela Silva, Ermelindo y Méndez Pallares, María Carmen. «Los espacios de la muerte». En La idea y el sentimiento de la muerte en la historia y en el arte de la Edad Media (II). Santiago de Compostela: Universidad de Santiago de Compostela, 1992, pp. 27-36.

Prigent, Daniel. «Les céramiques funéraires (XI ${ }^{\mathrm{e}}$-XVII ${ }^{\mathrm{e}}$ siècle)». En GaliniÉ, Henri y Zadora-Rio, Elisabeth (eds.). Archéologie du cimetière chrétien. Tours: Revue Archéologique du Centre de la France, 1996, pp. 215-224.

Quirós Castillo, Juan Antonio. «Trends and thoughts on the archaeology of Germanic cemeteries». Arqueología y Territorio Medieval, 2011, vol. 18, pp. 9-14. 
REIVINDICACIÓN DE ESTATUS Y COSTUMBRES FORÁNEAS EN EL REGISTRO FUNERARIO MEDIEVAL CASTELLANO. A PROPÓSITO DE DOS CASOS DE CANTABRIA

ENRIQUE GUTIÉRREZ CUENCA

Ravoire, Fabienne. "Melun (Seine-et-Marne), ancien prieuré Saint-Sauveur ( $\mathrm{X}^{\mathrm{e}}$-XVIII ${ }^{\mathrm{e}}$ siècles). Aperçu sur la céramique du prieuré». Bulletin du Centre d'Études Médiévales d'Auxerre, 2006, vol. 10 [doi: 10.4000/cem.445].

Redín Armañanzas, Ana. "Espuelas de Andosilla». En Caballeros y caballos entre 1212 y 1512. Pamplona: Museo de Navarra, 2012, pp. 40-41.

Rivero Sierra, Borja. «La heráldica del sepulcro del caballero de San Martín de Elines». ASCAGEN Revista de la Asociación Cántabra de Genealogía, 2013, vol. 9, pp. 11-32.

Robreau, Bernard. "L'église Saint-Lubin de Châteaudun (Eure-et-Loir)». Revue Archéologique du Centre de la France, 1984, vol. 23, n. ${ }^{\circ}$ 1, pp. 99-124.

Rodríguez Rodríguez, Adelaida. «Acicates». En Elorza Guinea, Juan Carlos (ed.). El Cid, del hombre a la leyenda. Valladolid: Junta de Castilla y León, 2007, p. 221.

Rodríguez Rodríguez, Adelaida. Memoria del tratamiento de conservación y restauración aplicado a acicates y fragmentos de ataúdes procedentes de la ex colegiata de San Martin de Elines, Valle de Valderredible, Cantabria. Burgos: 2002. Informe inédito, consultado en el archivo del Museo de Prehistoria y Arqueología de Cantabria.

Rodríguez Velasco, Jesús. «Para una periodización de las ideas sobre la caballería en Castilla (ca. 1250-1500)». En Lucía Mejías, José Manuel (ed.). Actas del VI Congreso Internacional de la Asociación Hispánica de Literatura Medieval. Alcalá de Henares: Universidad de Alcalá, 1997, vol. 2, pp. 1335-1346.

Roig Buxó, Jordi; Coll Riera, Joan Manel y Molina Vallmitjana, Josep Anton. «El vilatge medieval i l'església de Sant Esteve de Castellar Vell (Castellar del Vallès, Vallès Occidental)». Tribuna d'Arqueologia, 2002, vol. 1998-1999, pp. 305-322.

Roig Buxó, Jordi; Coll, Joan Manuel y Molina Vallmitjana, Josep Anton. «L'església de Sant Julià d'Altura (Sabadell, Vallès Occidental): resultats de les darreres intervencions arqueològiques (1998-1999)». Tribuna d'Arqueologia, 2003, vol. 1999-2000, pp. 255-272.

Sánchez Ameijeiras, María Rocío. "El arnés y el armamento del caballero medieval gallego (1350-1450)». Acta Historica et Archaeologica Mediaevalia, 1989, vol. 10, pp. 427-436.

SÁNChez Ameijeiras, Rocío. "Un espectáculo urbano en la Castilla medieval: las honras fúnebres del caballero». En NúNEzz Rodríguez, Manuel (ed.). El rostro y el discurso de la fiesta. Santiago de Compostela: Universidad de Santiago de Compostela, 1994, pp. 141-158.

Schweitz, Daniel. «Dépôts funéraires médiévaux en Vendômois et dans le Centre». Revue Archéologique du Centre de la France, 1981, vol. 20, n. ${ }^{\circ}$ 2, pp. 27-40.

Serrano Coll, Marta. «Espacios monásticos como locus sepulturae: enterramientos nobiliarios en el románico hispano». En García de Cortázar, José Ángel y Teja, Ramón (eds.). Monasterios y nobles en la España del románico: entre la devoción y la estrategia. Aguilar de Campoo: Fundación Santa María la Real, 2014, pp. 137-175.

Sesma Sesma, Jesús. "Acicates y espuelas de la sacristía del Espíritu Santo. Catedral de Tudela». En Caballeros y caballos entre 1212 y 1512. Pamplona: Museo de Navarra, 2012, pp. 38-39.

Sesma Sesma, Jesús. "Ajuar funerario de Juan Renalt de Ujué, padre e hijo». En Caballeros y caballos entre 1212 y 1512. Pamplona: Museo de Navarra, 2012, pp. 34-37.

Solaun Bustinza, José Luis. La cerámica medieval en el País Vasco (siglos VIII-XIII). Vitoria: Universidad del País Vasco-Gobierno Vasco, 2005.

Soler del Campo, Álvaro. «Acicate». En Zozaya, Juan (ed.). Alarcos. El fiel de la balanza. Toledo: Junta de Comunidades de Castilla-La Mancha, 1995, p. 197.

Soler del CAmpo, Álvaro. «Acicates (espuelas) del rey Fernando III el Santo». En Metrópolis Totivs Hispaniae. Sevilla: Ayuntamiento de Sevilla, 1999, p. 236.

Solórzano Telechea, Jesús Ángel. «Los extranjeros en las villas portuarias de la Costa Cantábrica en la Baja Edad Media». En Arízaga Bolumburu, Beatriz; Mariño Veiras, Dolores; Díez 
REIVINDICACIÓN DE ESTATUS Y COSTUMBRES FORÁNEAS EN EL REGISTRO FUNERARIO MEDIEVAL CASTELLANO. A PROPÓSITO DE DOS CASOS DE CANTABRIA ENRIQUE GUTIÉRREZ CUENCA

Herrera, Carmen; Solórzano Telechea, Jesús Ángel; Guijarro González, Susana y AÑíbarro Rodríguez, Jesús (eds.). Mundos medievales: espacios, sociedades y poder. Homenaje al Profesor José Ángel García de Cortázar, Tomo II. Santander: Universidad de Cantabria, 2012, pp. 1933-1947.

Solórzano Telechea, Jesús Ángel. «Villas y redes portuarias en la fachada Atlántica del Norte peninsular en la Edad Media». En Val Valdivieso, María Isabel y Martínez Sopena, Pascual (eds.). Castilla y el mundo feudal: homenaje al profesor Julio Valdeón. Vol. 1. Valladolid: Universidad de Valladolid, 2009, pp. 485-502.

Solórzano Telechea, Jesús Ángel. Santander en la Edad Media: patrimonio, parentesco y poder. Santander: Universidad de Cantabria-Ayuntamiento de Torrelavega, 2002.

Sopelana, Itxaso. Análisis de macrorrestos vegetales de Santa María de la Asunción. Vitoria: Universidad del País Vasco, 2013. Informe inédito.

Vallejo Naranjo, Carmen. La caballería en el arte de la Baja Edad Media. Sevilla: Universidad de Sevilla, 2013.

Zadora-Rio, Elisabeth; Galinié, Henri; Baron, Marie-Claude; Husi, Philippe; Jouquand, Anne Marie; Martineau, Marie Christèle; Mascla, Jean Marcel; Poirot, Agata; Rodier, Xavier y Theureau, Christian. «Fouilles et prospections à Rigny-Ussé (Indre-et-Loire), rapport préliminaire 1986-1991». Revue Archéologique du Centre de la France, 1992, vol. 31, pp. $75-166$. 
